\title{
ARTÍCULOS
}

\section{HISTORIA POLÍTICA DEL TUCUMÁN DURANTE EL SIGLO XVII. TRADICIONES EXPLICATIVAS Y NUEVAS PERSPECTIVAS DE INVESTIGACIÓN.}

\author{
Guillermo Nieva Ocampo \\ Universidad Nacional de Salta \\ guillermohis@yahoo.es \\ Daniela Alejandra Carrasco \\ Universidad Nacional de Salta \\ d.carrasco@usal.edu.ar
}

Resumen: El objetivo de este trabajo es exponer las diversas interpretaciones que se realizaron sobre la historia política del Tucumán durante el siglo XVII. A la luz del desarrollo historiográfico del siglo XX hasta nuestros días, proponemos, además, nuevas perspectivas de investigación que consideramos necesarias.

Palabras clave: Monarquía Hispana, Virreinato del Perú, Gobernación del Tucumán, Historia del Poder, siglo XVII.

Tittle: POLITICAL HISTORY OF TUCUMAN DURING THE $17^{\text {TH }}$ CENTURY. EXPLONATORY TRADITIONS AND NEW PERSPECTIVES OF INVESTIGATION.

Abstract: The objetive of this work is to expose the various interpretations that were made about the political history of Tucuman during the 17th century. In the light of the historiographic development of the $20^{\text {th }}$ century to the present day, we also propose new research perspectives that we consider necessary.

Keywords: Hispanic Monarchy, Viceroyalty of Peru, Government of Tucuman, History of power, $17^{\text {th }}$ century.

\section{La Monarquía Hispana y sus territorios: desplazamientos conceptuales}

En su gran mayoría los estudios realizados por americanistas locales o extranjeros sobre la historia política del Tucumán del siglo XVII se fungieron por los llamados "esquemas generales de ordenamiento", herederos de una historiografía de las instituciones político-administrativas, que abordaba la dimensión política

Recibido: 06-07-2020

Aceptado: 18-07-2020

Cómo citar este artículo: NIEVA OCAMPO, Guillermo y CARRASCO, Daniela Alejandra. Historia política del Tucumán durante el siglo XVII. Tradiciones explicativas y nuevas perspectivas de investigación. Naveg@mérica. Revista electrónica editada por la Asociación Española de Americanistas [en línea]. 2020, n. 25. Disponible en: <http://revistas.um.es/navegamerica>. [Consulta: Fecha de consulta]. ISSN 1989-211X. 
desde un paradigma estatalista ${ }^{1}$, ya que analizaban las instituciones hispanoindianas bajo el punto de vista objetivo y racional, empleando conceptos extemporáneos para la época, como funcionarios, burocracia, oligarquía, ley, administración, intervención estatal, estado colonial, entre otros². A su vez, desde un punto de vista que recuerda mucho más a la administración de los imperios decimonónicos, se ha enfatizado con ello que los territorios americanos eran meras colonias que dependían de la metrópoli española, y que sólo se buscaba un dominio económico sobre ellos, donde lo político únicamente se articulaba en función de esa realidad ("era más importante extraer minerales que gobernar y administrar", se decía) ${ }^{3}$. En suma, esta óptica debe enmarcarse en la lógica nacional, estatal, liberal o burguesa que, para el caso americano, la independencia y el desarrollo de nuevas naciones en el siglo XIX simplificaban el esquema europeo al establecer la existencia de dos realidades antagónicas e incompatibles: la colonia y el Estado independiente ${ }^{4}$.

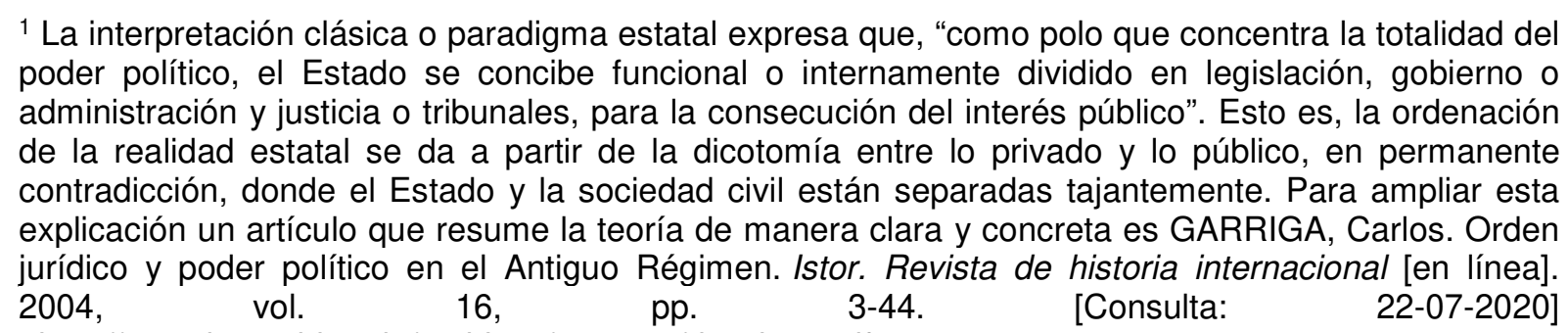
$<$ http://www.istor.cide.edu/archivos/num 16/dossier1.pdf>.

2 Por ejemplo: CORNEJO, Atilio. Descubrimiento, Conquista y Gobierno del Tucumán (1542-1776). En: LEVILLIER, Roberto. Historia Argentina. Buenos Aires: Plaza y Janes Editores, 1968; COROLEU, José y ARANDA, Manuel. América: historia de su colonización, dominación é independencia. Vol. 4. Montaner y Simón, 1896; FORTUNY, Pablo. Nueva Historia del Norte Argentino. Buenos Aires: Ediciones Theoría. 1911; FREYRE, Ricardo. Historia de la República del Tucumán. Buenos Aires: Imprenta y Editora de Coni Hermanos, 1911; FREYRE, Ricardo. El Tucumán del siglo XVI. Bajo el gobierno de Juan de Ramírez de Velasco. Buenos Aires: Imprenta y Editora de Coni Hermanos, 1915; LEVILLIER, Ricardo. Chile y el Tucumán en el siglo XVI (el conflicto Villagra-Núñez de Prado): refutación de las inexactitudes del señor don $T$. Thayer Ojeda en su análisis crítico de la Nueva crónica de la conquista del Tucumán. París: Le livre libre, 1928; LIZONDO BORDA, Manuel. Historia de la Gobernación del Tucumán, siglo XVI. Buenos Aires: Imprenta y Editora de Coni Hermanos, 1928; LUQUE COLOMBRES, Carlos y CORNEJO, Atilio. Don Gerónimo Luis de Cabrera y Salta. Cuarto centenario de las Fundaciones de Córdoba y Santa Fe (1573-1973). Buenos Aires: Academia Nacional de la Historia, 1974; LUQUE COLOMBRES, Carlos. Trejo y Córdoba. Córdoba: Dirección general de Publicidad de la Universidad Nacional de Córdoba, 1953; LUQUE COLOMBRES, Carlos. La diócesis del Tucumán y Córdoba. Córdoba, 1970; LUQUE COLOMBRES, Carlos. Para la historia de Córdoba. Córdoba: Secretaría y Ministerio de Educación y Cultura, 1971; SIERRA, Vicente. Historia de la Argentina, Consolidación de la labor pobladora (1600-1700) Libro Primero: Bajo el reinado de Felipe III. Buenos Aires: Editorial Científica, 1953; LOBOS, Héctor. Conquista y fundaciones del Tucumán y el Río de la Plata. En: Nueva Historia de la Nación Argentina Segunda Parte: La Argentina de los siglos XVII y XVIII. Buenos Aires: Editorial Planeta, 1999.

${ }^{3}$ GONZÁLEZ CUERVA, Rubén. Los virreinatos americanos: imagen, cortes y gestión de la distancia. Libros de la Corte [en línea]. 2017, Monográfico 5, año 9, pp. 9-26. [Consulta: 20-07-2020] Disponible en < https://revistas.uam.es/librosdelacorte/article/view/7812>.

${ }^{4}$ Ibídem. Vastas son las obras generales que responden a este esquema explicativo, sólo citaremos algunas: BERNARD, Carmen (comp.). Descubrimiento, conquista y colonización de América a quinientos años, México: Fondo de Cultura Económica, 1994; RAMOS PÉREZ, Demetrio. Historia de la colonización española en América. Madrid: Pegaso, 1947; PIETSCHMANN, Horts. El Estado y su evolución al principio de la colonización española de América. México: Fondo de Cultura Económica, 1989; ZAVALA, Silvio. Las instituciones jurídicas en la conquista de América. Editorial Porrúa, 1971; ZAVALA, Silvio. Ensayos sobre la colonización española en América. Secretaría de educación pública, 1972. 
Manuel Rivero Rodríguez expresó que la mayoría de los historiadores españoles del siglo XX, influenciados por las teorías de Max Weber y preocupados por explicar una Historia Nacional de la Edad Moderna, planteaban que desde la Edad Media hubo una tendencia histórica hacia la unificación institucional, política y social de España y de su Imperio, que pretendía dar forma a una nación integrada. Otra de las perspectivas que se desarrollaron fue la "confederal", sostenida por aquellos que consideraban que la monarquía española era una asociación de estados con un fin común, que se asemejaba al Imperio Británico, primando la diversidad entre ellos. Desde estas dos perspectivas se interpretó a la historia de España y a la gestión de sus territorios, que integraban la visión colonialista y la tensión centro-periferias ${ }^{5}$.

Hubo que esperar a finales del siglo XX para conocer trabajos que se alejaban de esas lógicas explicativas. En las últimas décadas se ha producido un giro en el análisis histórico, es decir, surgió un mayor interés por recobrar la dimensión política que antes había sido desplazada por los estudios de historia económica o social, que con frecuencia consideraron, erróneamente, que las acciones de los gobernantes del Antiguo Régimen seguían la lógica del capital ${ }^{6}$. De esta manera, los hechos históricos se están estudiando en su faceta política, pero desde un enfoque mucho más amplio y complejo ${ }^{7}$, como consecuencia de una saludable influencia de la sociología de las empresas y de los grupos, y también de la antropología política, la lingüística y la semiótica ${ }^{8}$. Una gran importancia tuvo, además, el diálogo con colegas pertenecientes a otras tradiciones historiográficas como los franceses e italianos $^{9}$.

${ }^{5}$ RIVERO RODRíGUEZ, Manuel. La reconstrucción de la Monarquía Hispánica: la nueva relación con los reinos (1648-1680). Revista Escuela de Historia [en línea]. 2013, vol. 12, p. 3. [Consulta: 15-072019] <http://www.scielo.org.ar/scielo.php?script=sci arttext\&pid=S1669-90412013000100002>.

${ }^{6}$ Es sabido que hubo un predominio de la historia social y económica, sobre todo la practicada por la escuela francesa de los Annales y por los materialistas británicos, con poco énfasis en la historia política durante las décadas de 1950 a 1980 . Para una rápida perspectiva del desarrollo de la historia social en las últimas décadas, véase: STONE, Lawrence. History and the social sciences in the twentieth century. The past and de present Revisited. Boston-Londres-Henley, 1981, pp. 45-73. Para una visión general de la historiografía británica, véase: MARWICK, Arthur. The nature history. Londres, 1970. Un ejemplo del rechazo al determinismo social y económico en las interpretaciones de la Edad Moderna, véase: HEXTER, Jack. Reappraisals in history. Chicago-Londres, 1979.

7 Hacia la década del '70 hubo una recuperación de la historia política, es decir: "el regreso de la política", "el retorno del sujeto", "la nueva historia política", véase: GIL PUJOL, Xavier. Tiempo de Política: Perspectivas Historiográfica sobre la Europa Moderna. Barcelona: Universitat de Barcelona, Servicio de Publicaciones, 2006; FERNÁNDEZ ALBALADEJO, Pablo. La historia política: de una encrucijada a otra. En: LÓPEZ, Roberto y LOPO GONZÁLEZ, Domingo (eds.). Balance de la historiografía modernista, 1973-2001. Homenaje al Profesor Dr. Antonio Eiras Roel. Santiago de Compostela: Xunta de Galicia, 2003, pp. 479-488.

${ }^{8}$ Sobre el "giro lingüístico", prácticas políticas culturales y discursivas, véase: SKINNER, Quentin. Visions of politics. Vol. I-III. Cambridge: Cambridge University Press, 2002. Sobre la política como cultura, véase: GILBERT, Felix. Politics or Culture? Reflections on Ranke and Burckhardt. New Jersey: Princeton University Press, 1990; BAKER, Keith (ed.). The political culture of the Old Regime. Vol. I de la Serie The French Revolution and the creation of modern political culture. Nueva YorkOxford: Pergamon, 1887. Sobre la diferencia entre "lo político" y "la política", véase: ROSANVALLON, Pierre. Por una historia conceptual de lo político. Buenos Aires: Fondo de Cultura Económica, 2003; SIRINELLI, Jean-François. El retorno de lo político. Historia Contemporánea. 1993, vol. 25, n. 9.

${ }^{9}$ Algunos ejemplos sobre los aportes de la microhistoria: GINZBURG, Carlo. Huellas. Raíces de un paradigma indiciario. Rosario: Tentativas, Prohistoria ediciones, 2004, pp. 69-113; GINZBURG, Carlo. Microhistoria: dos o tres cosas que sé de ella. Entrepasados. 1995, n. 8, pp. 51-73. LEVI, Giovani. 
De hecho, en el examen de la política antiguoregimental los cauces no institucionales, es decir que, el individuo y sus capacidades, los vínculos familiares, el patronazgo, las clientelas, los intermediarios, los grupos de elite, las redes de influencia $y$ todo un mundo de mediaciones $e$ intereses personales entre gobernantes y gobernados, entre la capital de la Monarquía y sus territorios, han pasado a ocupar el centro de la escena, completando o modificando el peso antes atribuido a los grandes organismos oficiales. Por ello, hoy se puede hablar de una 'rehumanización' de la historia política y de la historia en general ${ }^{10}$.

Uno de los puntos que resulta importante destacar de estos nuevos enfoques, es el avance sobre el campo de estudio del poder. Resulta lícito mencionar los aportes que realizaron historiadores como Gordon Craig, Benjamín Schwartz y Jacques Le Goff en la década de los '70. Estos destacaban la importancia de la política y de la diplomacia, "entendida como estudio del poder y de su práctica"11. Según Gil Pujol, en un estudio dinámico del proceso de toma de decisiones, se debe atender a los objetivos, prioridades e ideales de un gobierno en un sistema determinado, y cómo éstos se convirtieron en medidas políticas. A su vez, hay que observar cómo esas medidas se traducen en acciones $\mathrm{y}$, por último, qué consecuencias -buscadas $\mathrm{o}$ imprevistas- comportan, tanto para el propio gobierno como para la sociedad. Así, entran en juego las prioridades del momento, las circunstancias, el azar y la idiosincrasia individual ${ }^{12}$.

A los ojos de esta nueva perspectiva, algunos historiadores ofrecen una explicación pluricéntrica de hechos y procesos, ya que consideran que el poder circulaba por centros interconectados (interlinked centers), donde existía una negociación constante para mantener el sistema equilibrado entre todas sus partes, generándose conflictos jurisdiccionales. Sin embargo, en estas interpretaciones es imposible pensar que los soberanos de la Casa de Austria, la dinastía reinante en la Monarquía Hispana durante los siglos XVI y XVII, hubiesen podido dirigir y gobernar sus vastos territorios, ya que no existía un centro único de poder que pudiera subordinar al resto. Por lo que no se puede negar que la Monarquía, evidentemente, contaba con un "director de empresa", que se encargaba de garantizar un orden y de organizar la jerarquía interna. En este sentido, existía un centro político, no geográfico, y también un programa -laxo en algunas circunstancias- para impulsar a todo el conjunto. Asimismo, aquel conjunto participaba e interactuaba constantemente con ese centro, que se encontraba en la corte de Madrid y en el círculo selecto de las personas vinculadas con el rey ${ }^{13}$.

Sobre microhistoria. En: BURKE, Peter (ed.). Formas de hacer historia. Madrid: Alianza, 1993; GRENDI, Edoardo. Repensar la microhistoria. Entrepasados. 1996, n. 10, pp. 131-140. Sobre los enfoques más dinámicos y que prestan mayor atención a los individuos, véase: AUSTRAND, Françoise (dir.). Prosopographie et genèse de l'état moderne. Paris, 1986.

10 GIL PUJOL, Xavier. Notas sobre el estudio... Op. cit., p. 65.

11 Ibídem, p. 80. Sobre este punto, es importante destacar el retorno de las biografías históricas, véase: LE GOFF, Jaques. Comment Écrire une biographie historique aujourd'hui? Le Débat. París: Gallimard. 1989, n. 54, pp. 48-53.

12 GIL PUJOL, Xavier. Notas sobre el estudio... Op. cit., pp. 91-92.

${ }^{13}$ RIVERO RODRÍGUEZ, Manuel. La Reconstrucción de la Monarquía Hispánica... Op. cit., pp. 8-9. 
Existen, además, dos presupuestos interpretativos esenciales que explican el funcionamiento de la monarquía de los Austrias. Uno, sostiene que la construcción política fue la de una Monarquía Compuesta, es decir, la unión en la persona del rey de unos reinos que mantuvieron su identidad. Con lo cual, si América perteneció al conjunto de una inmensa y compleja monarquía esto obliga a una consideración global e interconectada de su historia, del mismo modo que invita a la comparación ${ }^{14}$. El otro, remite a la corte, a la comprensión de que el universo político del siglo XVII fue eminentemente cortesano y estaba basado en la idea de servicio al monarca: servir a fin de alcanzar la gracia real. Del mismo modo que en la corte real o las cortes provinciales de la monarquía, las diferentes cortes virreinales reproducían el comportamiento cortesano, junto a los usos y costumbres de cada reino ${ }^{15}$.

Por último, algunos trabajos provenientes de la historiografía francesa analizan la Monarquía de la Francia Moderna bajo el concepto de Monarchie Ecclésiale ${ }^{16}$ o monarquía eclesiástica. Este remite a describir una realidad donde el carácter eclesiástico se manifestó con la activa participación y acción que ejercieron en la corte los cardenales y otros miembros del clero, quienes muchas veces monopolizaron los asuntos de gobierno, sobre todo mediante su presencia en las capillas reales o como confesores del monarca. Esta óptica es, a nuestro entender, aplicable a los estudios de la Monarquía Hispana, ya que en su esencia presentó elementos similares.

\section{El virreinato del Perú}

Durante el reinado de Carlos $\mathrm{V}$, ante la imposibilidad de crear una corte itinerante que permitiera al monarca gobernar sus reinos, se introdujo la institución virreinal. De este modo, se pudo enviar a los distintos territorios un delegado del rey revestido de todas las atribuciones de la majestad soberana, es decir un virrey que se desempeñó como vicario real y suplente ideal del rey español ${ }^{17}$. Hay que tener en cuenta que los consejeros del emperador, y en particular el canciller Gattinara, recurrían con este a una antigua tradición perteneciente a la Corona de Aragón, que la había implementado en el Principado de Cataluña, en el año 1285, y que en el siglo XV la extendió a los reinos de Sicilia (1415) y de Cerdeña en (1417); luego, durante las primeras décadas del siglo XVI, se colocaron virreyes en Nápoles (1504) y Navarra (1512), así como en Aragón (1517) y en Valencia (1520) ${ }^{18}$.

\footnotetext{
${ }^{14}$ ELLIOTT, John. Europe of composite monarchies. Past and Present. 1992, vol. 137, n. 1, pp. 48-71. 15 CAÑEQUE, Alejandro. Cultura vicerregia y Estado colonial. Una aproximación crítica al estudio de la Historia política de la Nueva España. Historia Mexicana [en línea]. 2001, vol. LI, n. 1, pp.5-57. [Consulta: 04-07-2020]. Disponible en: <https://www.redalyc.org/pdf/600/60051101.pdf>.

16 Para profundizar este concepto, véase: BENOIST, Pierre. La Monarchie ecclésiale en France. Le Clergé de cour en France à l'époque moderne. Seyssel: Champs Vallon, collection Époques, 2013.

17 DE NARDI, Loris. Los virreinatos de Ssicilia y Perú en el siglo XVII. Apuntes sobre una comparación en el marco de la historia global de dos realidades solo geográficamente lejanas. Estudios políticos [en línea]. 2014, n. 45, pp. 55-75. [Consulta: 04-07-2020]. Disponible en $<$ http://www.scielo.org.co/scielo.php?script=sci abstract\&pid=S012151672014000200004\&lng=es\&nr $\mathrm{m}=$ iso\&tlng=es $>$.

${ }_{18}$ CARDIM, Pedro y PALOS, Joan-Lluis (eds.). El mundo de los virreyes en las Monarquías de España y Portugal. Madrid: Iberoamericana, 2012, p. 12.
} 
Por su parte, el Perú fue elevado a categoría de virreinato en 1542, y desde ese entonces comenzó a ser gobernado por un representante del monarca con título de virrey. 'Legislativamente' este personaje no era un dignatario más, sino más bien, el rey encarnado en Indias. En este sentido, los virreyes contaron con sus propias cortes virreinales, integradas, al igual que la del monarca, por su casa, su tribunal (la Audiencia) y sus consejos. Un centro de poder autónomo, en el que se concentraban las prerrogativas reales de provisión de oficios, gracias, mercedes, administración de la justicia, defensa y real patronazgo, entre otros. El virrey concentraba allí, al igual que el rey en Madrid, el suficiente poder como para tener un grupo de personas que circulaba a su alrededor y que se vinculaban con él por cuestiones personales, de afecto, amistad, y no tan solo por méritos profesionales ${ }^{19}$. En este contexto, el papel del virrey adquirió otra dimensión y su corte fue el espejo de la propia corte del rey, adquiriendo en este sentido, un desarrollo mayor a partir de $1580^{20}$.

No obstante, la 'institución virreinal' fue vista por la historiografía clásica como un elemento negativo, tanto en Nueva España como en el Perú21, válida para gobernar las 'colonias'. Desde el análisis de la historia de la administración, se consideró a la figura virreinal como un actor marginal, lejos del centro de interés, al que solamente prestaron atención las investigaciones sobre el desarrollo de la burocracia, la fiscalidad, la acción exterior, el ejército o la legislación. Se ha enfatizado con ello que el virreinato era la institución que estaba justificada por la larga distancia entre España y América $^{22}$. Este panorama, empero, fue puesto en tela de juicio por Ricardo Levene en la década de 1940 en la Argentina. Dicho historiador cuestionó los tópicos e ideas dominantes en la historiografía latinoamericana relativa a los años anteriores a la independencia. En sus investigaciones y artículos mostraba, entre otras cosas, que los reinos de Indias tuvieron no sólo una personalidad propia, sino también un lugar específico en el conjunto de la Monarquía Hispánica, una autonomía cercana a la independencia, siendo la institución virreinal uno de los mecanismos que impidió la transformación de aquellos territorios en simples colonias $^{23}$.

Precisamente, Víctor Tau Anzoátegui también indagó sobre la condición políticojurídica de las Indias, preguntándose si éstas eran provincias, reinos o colonias y expresó que desde el descubrimiento de América en 1492 hasta 1516, esos territorios habían sido considerados señoríos de los Reyes Católicos, y, luego, a partir de la segunda mitad del siglo XVI, fueron denominadas provincias, con el fin de individualizar las tierras que se fueron conquistando y poblando. A su vez, esta última designación era heredera de la tradición romana que perduró ${ }^{24}$ y que se

\footnotetext{
19 TORRES ARANCIVIA, Eduardo. Corte de virreyes: el entorno del poder en el Perú en el siglo XVII. Lima: Fondo Editorial PUCP, 2006, p. 34.

20 MARTÍNEZ MILLÁN, José. Cambios en la corte y en la forma de gobierno. Introducción. En: MARTÍNEZ MILLÁN, José y VICEGLIA, María Antonieta (dirs.). La monarquía de Felipe III: La corte. Vol. I. Madrid: Fundación MAPFRE-Instituto de Cultura, 2008, p. 132.

${ }^{21}$ CAÑEQUE, Alejandro. Cultura vicerregia y Estado colonial... Op. cit.

22 RIVERO RODRÍGUEZ, Manuel. La edad de oro de los virreyes. El virreinato en la Monarquía Hispánica durante los siglos XVI y XVII. Madrid: Ediciones Akal S.A., 2011, p. 10.

${ }^{23}$ LEVENE, Ricardo. Las Indias no eran colonias. Buenos Aires: Espasa-Calpe, 1951.

${ }^{24}$ En efecto, la voz provincia - utilizada imprecisamente en Castilla - parecía seguir en su uso indiano el modelo romano, que llevaba implícita la noción de distancia, que separaba lejanas comarcas del centro del poder político.
} 
refería a los grandes distritos desde un punto de vista territorial hasta el final de la época hispana ${ }^{25}$. De igual manera que Levene, este historiador afirmaba que la representación del rey a través del virrey en Indias significaba que su estatus superaba al de una mera colonia. Por su parte, Zacarías Moutoukias planteó que las Indias de América se integraron a la monarquía castellana, y que la justicia de los territorios se administró a partir del derecho existente, haciéndolo directamente a través de sus agentes ${ }^{26}$.

Retomando estos planteamientos, debemos entender que la política monárquica era proyectada hacia sus virreinatos a través de los patrones cortesanos que tejían sus redes personales, familiares y de amistad con el afán de ganarse el favor de los virreyes y así lograr algún control sobre esos reinos alejados geográficamente de Madrid y donde, en definitiva, la presencia estatal no existía aún. En este sentido, resulta necesario continuar profundizando en los estudios de las cortes virreinales, mayormente desarrollados para Nueva España ${ }^{27}$, y no tanto para el Perú. Desde el punto de vista de la corte virreinal como espacio político, varios historiadores concuerdan con el supuesto de que la corte no solo tuvo influencia decisiva en la vida política y administrativa, sino que proyectó un modelo de vida social y cultural. Asimismo, a través de estas cortes se lograba integrar los territorios y sus elites de poder a escala monárquica, virreinal y local. Es decir, era un punto de contacto entre rey, príncipe, virrey y súbditos, que servía como foro de luchas y toma de decisiones, como mercado de oficios, privilegios y otras mercedes reales, y como teatro de representación del rey²8.

Este último aspecto es relevante, ya que el virrey, además, era mucho más que un gobernador o un administrador, era un símbolo regio que debía hacer presente el

25 TAU ANZOÁTEGUI, Victor. La Monarquía. Poder central poderes locales. En: Nueva Historia de la Nación Argentina. Segunda parte: La Argentina de los siglos XVII y XVIII. Academia Nacional de la Historia. Buenos Aires: Editorial Planeta, 1999.

${ }^{26}$ MOUTOUKIAS, Zacarías. Gobierno y Sociedad en el Tucumán y el Río de la Plata, 1550- 1800. En: TANDETER, Enrique (dir.). Nueva Historia Argentina. La sociedad colonial. T. II. Buenos Aires: Sudamericana, 2000, pp. 358-411.

27 BÜSCHGES, Christian. Del criado al valido. Patronazgo de los virreyes de Nápoles y Nueva España (primera mitad del siglo XVII). En: CANTÚ, Francesca (ed.). Las cortes virreinales de la Monarquía española: América e Italia. Roma: Viella, 2008, pp. 157-181; BÜSCHGES, Christian. ¿Absolutismo virreinal? La administración del marqués de Gelves revisada (Nueva España, 16211624). En: DUBET, Anne y RUIZ IBAÑEZ, José Javier (coords.). Las monarquías española y francesa (siglos XVI-XVIII): ¿dos modelos políticos? Madrid: Casa de Velázquez, 2010, pp. 31-44; CAÑEQUE, Alejandro. The King's Living Image: The Culture and Politics of Viceregal Power in Colonial Mexico. Nueva York: Routledge, 2004.

28 Trabajos sobre el Perú durante los siglos XVII, véase: LATASA VASALLO, Pilar. Poder y favor en la corte virreinal del Perú: los criados del marqués de Montesclaros (1607-1615). Histórica (Perú). 2012 , vol. 36, n. 2, pp. 49-84; LATASA VASALLO, Pilar. La corte virreinal peruana: perspectivas de análisis (siglos XVI y XVII). En: BARRIOS PINTADO, Feliciano (coord.). El gobierno de un mundo: virreinatos y audiencias en la América Hispánica. España: Ediciones de la Universidad de Castilla-La Mancha, 2004, pp. 341-374; OSORIO, Alejandra. El rey en Lima, simulacro real y el ejercicio del poder en la Lima del XVII. En: MAZÍN, Óscar (ed.). Las representaciones del poder en las sociedades hispánicas. México: El Colegio de México-Centro de Estudios Históricos, 2012. Por otra parte, un trabajo de Cañeque para el virreinato de Nueva España: CAÑEQUE, Alejandro, El poder transfigurado. El virrey como ‘viva imagen del rey' en la nueva España de los siglos XVI y XVII. En: MAZÍN, Óscar (ed.). Las representaciones... Op. cit. 
poder de un monarca ausente. En ello residía la necesidad de montar una ritualidad o un ceremonial en torno a las fiestas, proclamaciones, lutos, nacimientos, matrimonios, celebraciones eclesiásticas, etc., es decir, no sólo como fiestas de entretenimiento, sino como instrumentos para una representación de la imagen viva del rey, con una profunda simbología del poder en esos territorios distantes, temas que hasta el día de hoy han sido poco estudiados ${ }^{29}$.

Finalmente, debemos decir que los intereses de los virreyes se limitaban, mayormente, a la capital peruana, a la jurisdicción de la Real Audiencia de Lima y, ocasionalmente, el Reino de Chile por cuestiones militares ${ }^{30}$. En los demás territorios, su potestad resultaba reducida. Por ello, en la práctica dependían de la habilidad que tuvieran para hacer valer su función como cabeza de la administración real en dichos territorios, por lo que debió valerse de las redes clientelares que se extendían hasta los gobiernos locales de las ciudades, para lograr cierta cohesión e integración. Por supuesto que esta situación debió contar también con una actitud conciliadora o negociadora por parte del virrey y de las elites sociales locales, que no siempre se verificó ${ }^{31}$.

\section{Gobernación del Tucumán: 'Instituciones civiles', actores y sociedad}

\subsection{El Gobernador}

Para reconstruir la dinámica y composición de la cultura política de la gobernación tucumana, es necesario estudiar tres elementos complejos que funcionaron en este periodo: el gobernador, el cabildo secular y la elite encomendera. Desde la "entrada a la tierra" por el sur del alto Perú, los primeros conquistadores y pobladores peninsulares, fueron fundando ciudades y asentándose en ellas, tal como mencionó Barriera "trazar cuadrícula, crear vecinos, hacer cabildo, designar oficios y señalar la jurisdicción"32, era el cometido de estos primeros

${ }^{29}$ BÜSCHGES, Christian. La corte virreinal como espacio político. El gobierno de los virreyes de la América hispánica entre monarquía, elites locales y casa nobiliaria. En: CARDIM, Pedro y PALOS, Joan-Lluis. Op. cit., pp. 319-344. Para profundizar en estos temas, véase: OSORIO, Alejandra. Inventing Lima: Baroque Modernity in Peru's South Sea Metropolis (The Americas in the early Modern Atlantic world). Reino Unido: Palgrave MacMillan, 2008.

${ }^{30}$ AMADORI, Arrigo. Dinámicas de poder entre Lima y Madrid durante el reinado de Felipe IV: entre el reformismo y la integración de la élite local en la Monarquía Hispana. En: MARTíNEZ MILLÁN, José; GONZÁLEZ CUERVA, Rubén y RIVERO RODRÍGUEZ, Manuel (dirs.). La corte de Felipe IV (16211665). Reconfiguración de la Monarquía Católica. Cortes virreinales y gobernaciones americanas. T. IV, vol. IV. Madrid: Polifemo, 2018, pp. 1957-2033.

${ }^{31}$ MERLUZZI, Manfredi. Los virreyes y el gobierno de las Indias. Las instrucciones al primer virrey de Nueva España (siglo XVI). En: CARDIM, Pedro y PALOS, Joan-Lluis. Op. cit., pp. 203-248. Sobre las estrategias de integración en Indias, véase: PONCE LEIVA, Pilar. La argamasa que une los reinos: gestión e integración de las Indias en la Monarquía Hispánica, siglo XVII. Anuario de Estudios Americanos [en línea]. 2017, vol. 74, n. 2, pp. 461-490. [Consulta: 20-07-2020] Disponible en: $<$ http://estudiosamericanos.revistas.csic.es/index.php/estudiosamericanos/article/view/718/718>;

NIEVA OCAMPO, Guillermo y CORREA, Marcelo. Agentes de gobierno en la Monarquía Hispana durante el siglo XVII: sujetos, vínculos y prácticas. Libros de la corte [en línea]. 2019, n. 18, pp. 55-58. [Consulta: 20-07-2020] Disponible en: <https://revistas.uam.es/librosdelacorte/article/view/11082>.

32 BARRIERA, Darío. Organizar la extensión. Occidentalización y equipamiento político del territorio. En: Abrir puertas a la tierra. Microanálisis de la construcción de un espacio político. Santa Fe, 15731640. Santa Fe: Museo Histórico Provincial Brigadier Estanislao López, 2013, pp. 97-133. 
agentes que adherían al proyecto de expansión de Felipe II.

Una vez superadas las disputas jurisdiccionales con Chile ${ }^{33}$, el Tucumán se convirtió en gobernación en $1563^{34}$, y en las décadas del siglo XVI fue gobernada por adelantados. A los gobernadores los debía elegir el rey, e interinamente podía hacerlo el virrey. Ciertamente en estos nombramientos hubo un espacio de negociación, el titular de un nombramiento regio siempre se impuso sobre el titular de una designación efectuada por el virrey. Un ejemplo de ello lo observamos con la superposición de designaciones para el Tucumán entre el virrey Toledo y Felipe II, estudiado por Levillier ${ }^{35}$.

En cuanto a la figura del gobernador, tanto en estudios clásicos como renovados, se ha afirmado que eran 'funcionarios coloniales' que reunieron amplios poderes de gobierno, justicia y guerra, con una limitación ejercida por parte de los organismos institucionales superiores: virrey y Audiencia; y por los organismos locales: cabildos y alcaldes. A esta red de limitaciones se sumaban las visitas y los juicios de residencia, que tendían a encauzar su labor y reducir o controlar su poder efectivo. En este sentido, existe un número considerable de publicaciones de americanistas que estudiaron las gobernaciones como una forma de administración del espacio, sin tener en cuenta, muchas veces, que fueron los gobernadores agentes del monarca en unas provincias donde primaban las prácticas informales para el ejercicio del gobierno ${ }^{36}$.

Hay que decir que el oficio de gobernador en Indias era considerado como una magistratura, con la cual se designaba, en un sentido amplio, la función de gobierno civil. Durante el siglo XVII dicho oficio fue ocupado en su mayoría por personajes con una amplia trayectoria militar, forjada en Europa o en la misma América. Algunos ejemplos son: Alonso de Ribera (1606-1611), combatió en Flandes y Francia;

33 Para profundizar sobre las disputas jurisdiccionales, véase: LEVILLIER, Roberto. Chile y el Tucumán... Op. cit.

${ }^{34}$ La Gobernación del Tucumán, Juríes y Diaguitas fue creada por Real Cédula de Felipe II el 29 de agosto de 1563, y, siete años después, se erigió el obispado con idénticos límites. La jurisdicción de la gobernación y el obispado abarcaban las actuales provincias del centro y noroeste de la actual República Argentina, a saber: Córdoba, Salta, Santiago del Estero (ciudad cabecera), Tucumán, La Rioja, Catamarca y Jujuy.

35 LEVILLIER, Roberto. Nueva crónica de la conquista del Tucumán. Vol. I-III. Buenos Aires: Editorial Nosotros, 1926-1931.

${ }^{36}$ Algunos ejemplos de las obras que presentan este esquema de interpretación son: FRADKIN, Raúl y GARAVAGLIA, Juan. La Argentina colonial. Buenos Aires: Siglo XXI, 2009; CASTRO OLAÑETA, Isabel. 'Vuestra Magestad se sirva de ordenar al Governador, que no apriete en las ordenanzas del visitador'. Gobierno colonial y poder local en la Gobernación del Tucumán (1603-1619). Bibliographica Americana. 2013, n. 9, pp 23-48; CARMIGNANI, Leticia. 'Soy en esta provincia muy odiado de los vecinos encomenderos'. El gobernador del Tucumán Alonso de Ribera y su proyecto Político (16051611). Memoria Americana [en línea]. 2005, vol. 23, n. 1, pp. 11-38. [Consulta: 15-10-2018] Disponible en: <http://ppct.caicyt.gov.ar/index.php/memoria-americana/article/view/5862/6183>. Y los clásicos ya citados: SIERRA, Vicente. Op. cit.; FORTUNY, Pablo. Op. cit.; FREYRE, Ricardo. Op. cit.; LIZONDO BORDA, Manuel. Op. cit., entre otros. Por su parte, Oscar Trujillo subrayó que el gobernador indiano fue un representante del poder central en zonas alejadas de las sedes virreinales. Es por esa razón que debemos estudiarlos como actores políticos, más que meros funcionarios. Véase: TRUJILLO, Oscar. Los Gobernadores de Buenos Aires a mediados del siglo XVII: mediación y conflicto en los confines de la Monarquía Hispánica. Historia, historias. 2014, vol. 2, n. 3, pp. 92-108. 
Francisco de Avendaño y Valdivia (1638-1640), combatió en Chile; Francisco Gil de Negrete, (1649-1651), se destacó en Flandes y Chile; Alonso de Mercado y Villacorta (primer gobierno desde 1655 hasta 1659, y segundo gobierno desde 1664 hasta 1670), participó en las campañas de Cataluña y Barcelona; Jerónimo Luis de Cabrera y Garay (primer gobierno desde 1640 hasta 1642 y segundo gobierno desde 1660 hasta 1662), nieto de conquistadores y fundadores, se destacó en las Guerras Calchaquíes y en la expedición sin éxito de la ciudad legendaria de los Césares; Juan Diez de Andino (1678-1681), actuó en la guerra contra Portugal; Tomás de Argandoña (1686-1691), fue Alférez de la Real Armada. Otros, por ejemplo, provenían de tradicionales familias nobles: Luis de Quiñones Osorio (16111619), fue señor de la casa y solar antiguo de San Román de los Quiñones y de la Villa de Quintanilla en el Reino de León; Juan Alonso de Vera y Zárate (1619-1627), fue el primer gobernador criollo y mestizo del Tucumán, hijo de Juana Ortiz de Zárate y Yupanqui, descendiente de la nobleza indígena altoperuana; Felipe de Albornoz (1627-1637), era hijo de un caballero toledano de la Orden de Calatrava, Francisco de Albornoz, y de Felipa Polo de Espinosa, sobrina del cardenal Diego de Espinosa, además, se desempeñó como paje y gentilhombre de cámara de Felipe III. En resumidas cuentas, hay que destacar que todos los personajes que desempeñaron el cargo de gobernador debieron contar, ya sea, con una lista de méritos y servicios por el cual ser premiados, o, debían provenir de alguna familia más o menos acomodada y con contactos en la corte de Madrid, para así lograr obtener algún nombramiento. Asimismo, gozar de un cargo en Indias, les serviría como puntapié inicial para obtener alguna provisión o merced mayor, o en otro territorio más próspero. Por ello fue recurrente, además, que los gobernadores solicitasen al monarca como premio a sus servicios un hábito de la Orden de Santiago, algo que les brindaba mucho prestigio y honorabilidad ${ }^{37}$.

Cada gobernador debió negociar con las élites locales, es decir, con los encomenderos y miembros del cabildo secular, además de los agentes eclesiásticos, para lograr llevar a cabo sus proyectos políticos que muchas veces se alineaban con el programa monárquico, $\mathrm{o}$, a veces, solo con sus intereses personales. Esta sociedad, como cualquier otra, se articulaba a través de las relaciones personales que abarcaban el orden moral - en manos de la iglesia, aunque con los límites del patronato regio -, el poder económico (detentado por las elites encomenderas), y el poder político, repartido en distintos niveles de cargos, de funciones y espacios. En cada uno de los órdenes actuaban elementos como el honor, el prestigio, la

\footnotetext{
37 Para profundizar sobre la trayectoria y labor que desempeñaron los gobernadores del siglo XVII, véase: CARRASCO, Daniela. Conflictos de poder en el Tucumán Hispano: el gobernador Alonso de Ribera y el obispo Hernando de Trejo y Sanabria. Libros de la corte [en línea]. 2018, n. 16, año 10, pp. 8-25. [Consulta: 20-07-2020] Disponible <https://revistas.uam.es/librosdelacorte/article/view/9612>; CARRASCO, Daniela. La Gobernación del Tucumán y su organización política durante el reinado de Felipe III (1598-1621). En: NIEVA OCAMPO, Guillermo; GONZÁLEZ FASANI, Ana Mónica y CHILIGUAY, Alejandro. La antigua gobernación del Tucumán: política, sociedad y cultura, siglos XVI al XIX. Salta: Milor, 2020, pp. 141180; NIEVA OCAMPO, Guillermo. El Tucumán en tiempos del conde duque de Olivares (1621-1643). En: NIEVA OCAMPO, Guillermo [et. al.]. Ibídem, pp. 181-222; BORELLA, Jezabel y CORREA, Marcelo. La gobernación del Tucumán durante la segunda parte del reinado de Felipe IV (1643-1665). En: NIEVA OCAMPO, Guillermo [et. al.]. Ibídem, pp. 223-248; NIEVA OCAMPO, Guillermo y VILLANUEVA, Javier. El Tucumán en tiempos de Carlos II (1665-1700). En: NIEVA OCAMPO, Guillermo [et. al.]. Ibídem, pp. 249-294.
} 
parentela, el servicio - real y a Dios -, la lealtad-fidelidad, etc. En esas condiciones, el servicio actuaba como un mecanismo de ascenso social, como un instrumento de idealización de las elites, de profesionalización administrativa y de integración social y política, a través de la práctica de la recomendación, que reforzaba la hegemonía de la Corona tanto en Europa como en América. Por otro lado, esta práctica generalizada estaba vinculada al ejercicio de la justicia, virtud esencial de todo príncipe cristiano, entendida como retribución, merced o gracia, justamente, por los servicios prestados a Dios y a la república, contrario al "deservicio", que conllevaba un castigo ${ }^{38}$.

\subsection{El cabildo y la elite encomendera}

Desde un principio, los conquistadores recibieron junto con los solares, trazas urbanas, tierras en sus alrededores para explotarlas y abastecerse. El Tucumán fue una zona con elevado número de pobladores indígenas y escasos recursos mineros, por lo que se crearon las encomiendas de servicio. La obtención de encomiendas les daba a dichos conquistadores un medio para su sustento y el necesario prestigio social para instalarse en un nivel superior de esas minúsculas ciudades. La historiografía clásica planteó, en este sentido, que las encomiendas garantizaron una posición de poder a los colonizadores; en primer lugar, un poder económico, al facilitar el trabajo de los indios en las tierras que ellos mismos no querían trabajar, por ser impropio de hidalgos, condición que habían traído de España o que ganaron en América; en segundo lugar, poder político, en la medida en que reforzaba su condición de vecinos y su derecho a participar en el gobierno comunal. Por aquellos tiempos, el prestigio lugareño se construía a través del ejercicio de importantes funciones de gobierno, civil o eclesiástico, tales como: tenientes de gobernadores, oficiales de la Real Hacienda, miembros del cabildo eclesiástico y del cabildo secular ${ }^{39}$.

A principios del siglo XVII, la Corona había iniciado una campaña para suprimir la encomienda de servicio, puesto que los encomenderos vulneraban los 'derechos' de los indios, no los instruían religiosamente, se apoderaban de sus tierras y los trasladaban lejos de sus aldeas. En este sentido, sobreabundan los informes negativos realizados por los oficiales reales, por numerosos clérigos e incluso por particulares acerca del trato brindado por los españoles a los naturales. $Y$ de este

38 Sobre el concepto de servicio en las sociedades de Antiguo Régimen, véase: ESTEBAN ESTRÍNGANA, Alicia. El servicio: paradigma de relación política en los siglos XVI y XVII. En: Servir al Rey en la Monarquía de los Austrias. Medios, fines y logros del servicio al soberano en los siglos XVI y XVII. Madrid: Sílex ediciones S.L., 2012, pp. 11-45; GIL PUJOL, Xavier. Integrar un mundo. Dinámicas de agregación y de cohesión en la Monarquía de España. En: MAZIN, Óscar y RUIZ IBÁÑEZ, José Javier (eds.). Las Indias Occidentales Procesos de incorporación territorial a las Monarquías Ibéricas. México: El Colegio de México, 2012, pp. 69-108; PARDO MOLERO, Juan Francisco y LOMAS CORTÉS, Manuel. Ministros idóneos. El marco del servicio al rey en la Monarquía Hispana. En: Oficiales reales. Los ministros de la Monarquía Católica (siglos XVI y XVII). Valencia, Universidad de Valencia-Red Columnaria, 2012.

39 NIEVA OCAMPO, Guillermo y CARRASCO, Daniela. El Tucumán de Felipe IV. En: MARTÍNEZ MILLÁN, José; GONZÁLEZ CUERVA y Rubén, RIVERO RODRÍGUEZ, Manuel (dirs.). Op. cit., pp. 2091-2137. 
tema también se ha ocupado bastante la tradición historiográfica de la época ${ }^{40}$.

Un ejemplo claro de dicha campaña fue la gestión que llevó a cabo el gobernador Alonso de Ribera, quien en reiteradas ocasiones denunció el maltrato indígena por parte de los encomenderos, manifestando que los últimos no respetaban los días de descanso de los indios, ni el tiempo para ocuparse de sus sementeras, ni tampoco de sus tierras. El gobernador señalaba, además, que los indios eran vasallos de los encomenderos y no del monarca y aducía que esa situación solamente podía modificarse con la participación de nuevos agentes que fueran foráneos y desinteresados, porque los actuales eran vecinos que impedían la aplicación de la justicia real ${ }^{41}$. En consecuencia, con Ribera se acentuó una tradición de la Corona por mermar el poder de los vecinos encomenderos, $y$, a medida que fue transcurriendo el siglo, se consiguió poco éxito, ya que a finales del siglo XVII la elite criolla estaba consolidada ${ }^{42}$.

Por su parte, los miembros del cabildo secular, alcaldes o regidores, conformaron un grupo poco homogéneo y no faltaron divergencias que derivaron en enfrentamientos de un grupo de familias contra otros o con los mismos gobernadores. A inicios del siglo XVII, una de las familias más influyente de la sociedad tucumana era la de los Tejeda, casa fundada por don Tristán, oriundo de Deza y participante de la campaña de conquista del Tucumán junto a Jerónimo Luis de Cabrera. Los miembros de esta familia ocuparon plazas en el cabildo de Córdoba, fundaron monasterios de monjas (Leonor de Tejeda, el monasterio de las dominicas; $y$, Juan de Tejeda, fundador de las carmelitas). Hacia 1620, esta familia era la mejor relacionada, en virtud de matrimonios y negocios. Para la década del '20, este proceso de ascenso social y político de europeos de escasos recursos había concluido. Esta situación se manifestó, entre otras exteriorizaciones, a través de la composición de los sucesivos cabildos, en los cuales ya no se encuentra a individuos que no estén asociados a grupos familiares destacados en lo económico, lo político y lo ritual. A partir de entonces, se consolida una elite política, económica y sociocultural que impone su impronta al resto de la sociedad ${ }^{43}$. Debemos hacer mención, además, que luego de la segunda década del seiscientos, la venta de

\footnotetext{
40 Sobre el régimen de encomiendas, desde un punto de vista económico y social, en los siglos XVI y XVII, citaremos algunos ejemplos: LORANDI, Ana María. El servicio personal como agente de desestructuración en el Tucumán colonial. Revista Andina. 1988, n. 1, año 6. PALOMEQUE, Silvia, El mundo indígena. Siglos XVI-XVII. En: TANDETER, Enrique (dir.). Nueva Historia Argentina. Op. cit., pp. 89-143; DOUCET, Gastón. En torno a la población aborigen y a las encomiendas de indios del antiguo Tucumán. Revista de Indias. 1987, vol. 179, n. 47, pp. 253-313; ANELLO, Alejandra; DOUCET, Gastón y PALOMEQUE, Silvia. Los pueblos de indios del Tucumán colonial: pervivencia y desestructuración. Jujuy: Universidad Nacional de Jujuy, 2002; GONZÁLEZ RODRÍGUEZ, Adolfo. La encomienda en el Tucumán. Sevilla: Diputación de Sevilla, 1984; FARBERMAN, Judith y BOIXADÓS, Roxana. Sociedades indígenas y encomienda en el Tucumán colonial. Un análisis comparado de la visita de Luján de Vargas. Revista de Indias. 2006, vol. LXVI, n. 238; CASTRO OLAÑETA, Isabel. "Donde están situados los mas yndios de la jurisdiccion desta ciudad". Un acercamiento etnohistórico a las encomiendas y pueblos de indios del Río Salado. Santiago del Estero entre fines del siglo XVI y principios del siglo XVII. Surandino monográfico [en línea]. 2013, vol. 3. [Consulta: 25-08-2020] $<$ http://revistascientificas.filo.uba.ar/index.php/surandino/article/view/477>.

${ }^{41}$ NIVEA OCAMPO, Guillermo y CARRASCO, Daniela. Op. cit., p. 2096.

${ }^{42}$ Felipe de Albornoz hacia 1627 continuaba constatando la supervivencia de la encomienda de servicio, aunque menguada por la caída demográfica de la población indígena. Ibídem.

43 Ibídem, p. 2100.
} 
cargos en el cabildo se volvió más constante, aunque esta práctica estuvo avalada por una Real Cédula de Felipe III en 1609, sobre todo para la venta de regidurías ${ }^{44}$. La compra fue una nueva forma de acceder a los cargos públicos, altamente codiciados por los vecinos ya que también concedía prestigio social.

No obstante, carecemos de trabajos orgánicos que realicen un análisis minucioso de la composición y la dinámica política del Tucumán en general, y del interior de los cabildos y su proyección social, en particular. Para el Jujuy, Juan Pablo Ferreiro dedicó un artículo a la política y al parentesco de las familias notables del siglo XVII, manifestando que fueron tres elementos principales los que estructuraron la nobleza local: la gran propiedad terrateniente, el servicio militar y el cargo público. También estudió la composición del cabildo jujeño, las funciones de sus miembros (designaciones, duración, competencias, etc.), y remarcó que hacia 1610/1615 se observa que en el cabildo de dicha ciudad había un fenómeno similar al que Góngora analizó para el cabildo de Santiago de Chile en la misma época, esto es, la afirmación del fiscalismo monárquico a expensas del principio electivo municipal, es decir, el remate de cargos que pocos años atrás eran electivos. La explicación de este autor es que se daba por una doble política de la corona a través de la Real Audiencia con respecto a los cabildos. Por un lado, aumentar el tesoro real a partir de la subasta de un número creciente de cargos municipales, y por otro, continuar el proceso, comenzado a mediados del siglo XVI, de limitación de poder de las aristocracias locales, o, mejor dicho, de evitar que estas se transformen en una nobleza no cortesana basada en la propiedad territorial y con el control político de vastas zonas a través de la participación en el municipio. Otro asunto que merece destacar del trabajo de Ferreiro es que, para él, la concentración de poder en pocas manos, familias, o redes, significó que se produzca la consolidación de un patrón de parentesco particular: la casa ${ }^{45}$.

Por otra parte, contamos con algunos trabajos que estudiaron los cabildos y su funcionamiento, pero enfocados en los siglos XVIII y principios del siglo $\mathrm{XIX}^{46}$. En

\footnotetext{
44 Todos los oficios vendibles y renunciables de la gobernación se sacaban a pregón en las ciudades donde vacaban y el remate se efectuaba en Potosí. Los títulos se otorgaban en Lima y la confirmación en Madrid. Esta práctica luego se extendió a otros oficios, incluso hasta el de gobernador se llegó a vender. Esto no significaba una lógica corrupta, sino que eran medios propios de la época. Véase NIEVA OCAMPO, Guillermo. El Tucumán en tiempos de Olivares..., Op. cit.

${ }^{45}$ FERREIRO, Juan Pablo. Todo queda en familia... política y parentesco entre las familias notables del Jujuy del XVII. En: Beneméritos, aristócratas y empresarios: identidades y estructuras sociales de las capas altas urbanas en América Hispánica. Frankfurt-Madrid: Ververt, Verlagsgesellschafl, 1999, pp. 251-273.

${ }^{46}$ En estos trabajos se estudia al cabildo como una institución administrativa. Es muy frecuente el uso del término 'funcionario' y 'oligarquía' para referirse a sus miembros. Véase: ARAMENDI, Bárbara ¿Poder local versus poder real? Conflictos entre el Cabildo de Córdoba y el Gobernador don Joaquín Espinosa y Dávalos. Andes [en línea]. 2011, vol. 22 [Consulta: 20-10-2018] Disponible en: $<$ https://www.redalyc.org/pdf/127/12719967003.pdf>.; MARCHIONI, Marcelo. Una elite consolidada: el Cabildo de Salta en tiempos de cambios. En: MATA DE LÓPEZ, Sara (comp.) Persistencias y cambios: Salta y el Noroeste argentino. 1770-1840. Rosario: Prohistoria y Manuel Suárez, 1999, pp.177-217; Un análisis desde el punto de vista económico del Cabildo de Córdoba, véase: GONZÁLEZ RODRÍGUEZ, Adolfo. El cabildo de Córdoba durante el siglo XVI: encomenderos, propietarios de tierras, tratante de negros y comerciantes. Análisis de un grupo de poder. Córdoba: Centro de estudios genealógicos de Córdoba, 1986. Sobre el tema, además, encontramos información en los trabajos desde la historia de las instituciones y del derecho que citamos al inicio de
} 
este sentido, continúa siendo una deuda historiográfica examinar las actitudes y decisiones de las élites de las ciudades de la gobernación tucumana del siglo XVII, sobre todo desde el punto de vista de sus redes de relaciones, negocios y parentesco, a toda escala jurisdiccional, integrándose en redes de poder más amplias que las conectaban con la corte virreinal o con la corte de Madrid.

En cuanto a los vínculos y negocios, merece la pena destacar que la sociedad del Tucumán estuvo muy ligada a su dependencia jurisdiccional superior más próxima, la Audiencia de Charcas, y con ello a sus oidores. Por ejemplo, Felipe de Albornoz tenía la intención de combatir las arbitrariedades de las elites que dominaban la región para "asentar mejor la autoridad del rey, sin que pudiesen intervenir los oidores de la Audiencia de Charcas, celosos defensores del interés de los señores del Tucumán, con quienes estaban asociados" ${ }^{27}$. Es decir, la misma Audiencia había permitido que se pudiesen elegir alcaldes entre los naturales de las ciudades, cuando esto no estaba permitido desde la promulgación de la Real Cédula de Felipe II en 1569. Un elemento que ayudaría al gobernador a contrarrestar el poder de las elites locales que contaban con el apoyo de Charcas, era el teniente de gobernador ${ }^{48}$, por lo cual solicitó la aprobación del rey para poder designarlos sin la intervención de la Audiencia, aspecto que no fue consentido ni por el Consejo de Indias, ni por Felipe IV. Evidentemente necesitamos más trabajos que aborden la fluctuante relación, desde su dimensión política, entre los vecinos tucumanos y los oidores de Charcas, ya que durante el siglo XVII mientras cambiaban los gobiernos locales, se modificaban las orientaciones de los monarcas y sus respectivos equipos de gobierno en Madrid, y, en definitiva, esto influía en el trazo de aquellas alianzas o disputas ${ }^{49}$.

este artículo. Un trabajo más reciente y general desde esta óptica, véase: SÁNCHEZ-ARCILLA BERNAL, José, LOSA CONTRERAS, Carmen y MORANCHEL POCATERRA, Mariana. Instituciones políticos-administrativas de la América Hispana (1492-1810). Madrid: Universidad Complutense de Madrid, 1999.

47 NIEVA OCAMPO, Guillermo. El Tucumán en tiempos de Olivares... Op. cit.

48 Podemos mencionar algunos trabajos sobre tenientes de gobernador que observan su figura como agentes mediadores de poder. Darío Barriera estudió a los tenientes en la Santa Fe de la gobernación de Buenos Aires del siglo XVII, advirtiendo que los Austrias querían evitar la superposición entre el servicio real y los intereses locales; por ello, buscaron asegurar una actuación "imparcial" de dichos tenientes, manteniéndolos aislados de su entorno y disponiendo, a partir de la Real Cédula de 1569, que estos no debían ser vecinos de la ciudad de donde ocupasen el cargo, ni residir en ella, ni estar emparentado con los vecinos. En el caso Tucumano, observamos prácticas contrarias a las estipuladas por la Real Cédula. Cfr. BARRIERA, Darío. Resistir al teniente con la letra del Rey: la conflictiva relación del cabildo de Santa Fe con la gobernación del Río de la Plata durante los años 1620. En: DALLA CORTE, Gabriela [et. al.] (coords.). Homogeneidad, diferencia y exclusión en América. X Encuentro-Debate América Latina, ayer y hoy. Barcelona: Universitat de Barcelona, 2006, pp. 65-71. Para Corrientes podemos mencionar como ejemplo el trabajo de COLLINO, Fernando. Un teniente de gobernador de Corrientes en el temprano S. XVII. Revista Escuela de Historia. 2016, vol. 15, n. 2. Un caso tucumano fue estudiado por ARANA, Margarita. Enfrentamientos en el Cabildo entre miembros de la elite de San Miguel de Tucumán en 1654: la elección del teniente de gobernador. Andes. 2013, vol. 24.

49 Un estudio sobre los vínculos entre el Tucumán y Charcas desde una dimensión social, véase: OLIVIETO, Guillermina y CASTRO OLAÑETA, Isabel. Entre Charcas y el Tucumán. Las sociedades indígenas frente a los sistemas de dominación desde una perspectiva etnohistórica, siglos XV al XVIII. Memoria Americana. Cuadernos de Etnohistoria [en línea]. 2019, vol. 27, n. 1, pp. 5-10. [Consulta: 20-07-2020]. $<$ http://revistascientificas.filo.uba.ar/index.php/MA/article/view/6329> 
Al realizar este recorrido por las tradiciones explicativas sobre el periodo advertimos que debemos profundizar algunos temas, efectuar otros casi sin explorar y comprender a la sociedad y su mundo cultural como el resultado de transacciones constantes entre los individuos, mediante la manipulación, la elección y decisión frente a la realidad normativa, que permitía muchas posibilidades de interpretación y libertades personales. En este sentido, el historiador debe interesarse por "la definición de las ambigüedades del mundo simbólico, la pluralidad de interpretaciones posibles del mismo y la lucha que entablaba por los recursos tanto simbólicos como materiales ${ }^{50}$. Por otra parte, al igual que en los estudios sobre cortes virreinales, es importante reflexionar sobre el poder, atravesado por el concepto de honor, que se expresaba a través de la simbología política en las fiestas y ceremonias urbanas. Hay que recordar que el ceremonial de las cortes virreinales se reproducía también en las ciudades y que funcionaba como elemento de integración y de identidad política, temas poco abordados ${ }^{51}$.

\section{Clero y política}

Dentro de ese sistema articulado en cortes $^{52}$, el ejercicio del gobierno por parte de los ministros y oficiales reales en los distintos reinos de la Monarquía contó en todo momento con la práctica de la negociación con los patronos locales, y no sólo durante periodos de conflicto ${ }^{53}$. Tal como hemos mencionado, dicha política de 50 LEVI, Giovani. Op. cit., pp. 120-121.
51 En el capítulo cuatro de la obra "EI espacio público en las ciudades hispanoamericanas...", Carlos
Page trabajó sobre las funciones cívicas de la Plaza Mayor de Córdoba, las festividades cívico-
religiosas, las celebraciones reales como coronaciones y defunciones de reyes, lutos y bodas durante
el reinado de Felipe IV, juras y funerales desde Carlos II Hasta Fernando VII, la figura del Alférez Real
y el estandarte de la ciudad, los toros, las cañas y los fuegos artificiales, entre otros temas: PAGE,
Carlos. El espacio público en las ciudades Hispanoamericanas. El caso de Córdoba (Argentina),
siglos XVI a XVIII. Córdoba: Báez Ediciones, 2008. Sobre la proclamación de Carlos IV en Córdoba,
debemos mencionar otro trabajo del mismo autor: PAGE, Carlos. Las proclamaciones en Córdoba del
Tucumán. Revista Computense de Historia de América [en línea]. 2004, vol. 30, pp. 77-94. [Consulta:
19-07-2020]. Disponible

en phttps://revistas.ucm.es/index.php/RCHA/article/view/RCHA0404110077A/28599 >; Un trabajo sobre Clarisa. Pobres, negros y esclavos. Música religiosa en Córdoba del Tucumán (1699-1840). Córdoba: Editorial Brujas, 2017.

52 Véase MARTÍNEZ MILLÁN, José. La corte de la monarquía hispánica. Studia historica. Historia moderna. 2006, n. 28, pp. 17-61; MARTíNEZ MILLÁN, José y FERNÁNDEZ CONTI, Santiago (coords.). La Monarquía de Felipe II: La Casa del Rey. Vol. I. Madrid: Fundación Mapfre, 2005, pp. 17-52.

53 "En el marco de un imperio negociado en el que los acuerdos funcionales entre sus múltiples polos de poder estuvieron a la orden del día, contribuyendo al mantenimiento del vínculo político entre la Corona y las posesiones americanas, los servidores reales más encumbrados del gobierno colonial podían constituirse alternativamente en factores de estabilidad o en detonantes de enfrentamientos y rebeliones, dependiendo de cómo administraran las instrucciones recibidas. De hecho, lo que con los debidos reparos podríamos denominar una "política colonial" elaborada en la corte, en la práctica solía ser alterada por los representantes reales, quienes muchas veces procuraban acercar intereses no siempre conciliables". AMADORI, Arrigo. No es menos servicio el diferir que el ejecutar: el programa fiscal de Felipe IV para el Perú y la gestión del virrey Chinchón (1629-1641). Historia. 2013, n. 46, pp. 7-37. Véase, además, ESTEBAN ESTRÍNGANA, Alicia. El consenso como fundamento de la cohesión monárquica: la operatividad política del binomio protección-defensa en los Países Bajos en el siglo XVII. En: GUILLAMÓN ÁLVAREZ, Francisco y RUÍZ IBÁÑEZ, José Javier. Lo conflictivo y 
negociación es un asunto particularmente significativo cuando se analiza el gobierno en los territorios indianos ${ }^{54}$, un espacio en el que se ha reconocido en modo categórico el peso de las elites locales como mediadores sumamente influyentes ${ }^{55}$.

No obstante, muchas veces se olvida que la Monarquía Hispana, más allá de su carácter dinástico, agregativo, administrativo o fiscal, se definía por una concepción teológica que había madurado en los siglos finales de la Edad Media. Según ella, el reino era considerado un pueblo elegido por Dios y el monarca era quien debía dirigirlo a la salvación. De hecho, las Partidas de Alfonso X dedican su primera parte a presentar al rey castellano como protector de la Iglesia y del clero, y a este último como sus auxiliares naturales ${ }^{56}$. Un asunto que los reyes de la Casa de Austria exaltaron durante el siglo XVII, sobre todo, con la difusión de una imagen piadosa, asociada al culto eucarístico. De este modo, la monarquía de los Habsburgo debe ser considerada una "monarquía eclesiástica", como expresamos al inicio de este artículo. Es decir, que fue asistida por un "clero de corte", nucleados sobre todo en la Real Capilla, cuyos miembros solían recibir misiones y oficios administrativos en los Consejos ${ }^{57}$.

En los distintos reinos de aquella Monarquía se replicaba la presencia de un clero cortesano que asistía a los virreyes, una cuestión muy poco estudiada, sobre todo en los casos americanos y mayormente en el limeño, a pesar de que la historia política virreinal peruana se ha visto beneficiada en las dos últimas décadas con los ya citados estudios que realizaron Pilar Latasa, Eduardo Torres Arancivia, Alejandra Osorio y Arrigo Amadori, quienes han incorporado, al tradicional análisis institucionalista de las carreras de los oficiales reales, el examen del entorno doméstico de los virreyes, es decir, de su corte, deteniéndose en su composición,

lo consensual en Castilla: sociedad y poder político, 1521-1715: homenaje a Francisco Tomás y Valiente. Murcia: Universidad de Murcia, 2001, pp. 325-276.

54 Véase TURNER BUSHNELL, Amy y GREENE, Jack. Peripheries, Centers and the Construction of Early Modern American Empires. An Introduction. En: DANIEL, Christine y KENNEDY, Michael (eds.). Negotiated Empires: Centres and Peripheries in the Americas, 1500-1820. Nueva York-Londres, 2002, pp. 1-15; AMADORI, Arrigo. Negociando la obediencia. Gestión y reforma de los virreinatos americanos en tiempos del conde-duque de Olivares (1621-1643). Madrid: CSIC-Universidad de Sevilla, 2013.

${ }^{55}$ Sobre el tema véase, BERTRAND, Michel. Poder peleado, poder compartido: familias y Estado en la América española colonial. En: MOLINA PUCHE, Sebastián e IRIGOYEN LÓPEZ, Antonio (ed.). Territorios distantes, comportamientos similares. Familias, redes y reproducción social en la Monarquía Hispánica (siglos XIV-XIX). Murcia: Edit.UM, 2009, pp. 217-236.

${ }^{56}$ MAZÍN, Óscar. Representaciones del poder episcopal en Nueva España (siglo XVII y primera mitad del siglo XVIII). En: Las representaciones del poder... Op. cit., p. 374.

57 De hecho, entre los espacios más relevantes del entorno de gobierno vicerregio se encontraba la capilla. Se trataba de un departamento de la casa real, núcleo doméstico de servicio en el contexto de la corte, que en España había definido sus características, competencias y obligaciones en un largo proceso que cubre casi dos siglos, desde el reinado de Juan II (1406-1454) hasta el de Felipe II (1556-1598). NOGALES RINCÓN, David. La representación religiosa de la monarquía castellanoleonesa: la Capilla Real (1252-1504) [tesis doctoral]. Madrid: Universidad Complutense de Madrid, 2009; GARCÍA GARCÍA, Bernardo José y CARRERAS ARES, Juan José. La Capilla Real de los Austrias: música y ritual de corte en la Europa Moderna. Madrid: Fundación Carlos de Amberes, 2001; PIZARRO LLORENTE, Henar. La capilla real, espacio de la lucha faccional. En: MARTÍNEZ MILLÁN, José y FERNÁNDEZ CONTI, Santiago (dirs.). Op. cit., pp. 143-151; NEGREDO DEL CERRO, Fernando. Los predicadores de Felipe IV. Corte, intrigas y religión en la España del Siglo de Oro. Madrid: Actas, 2006. 
función y dinámica, tanto simbólica como efectiva.

Lo cierto es, que se trató de un espacio relevante, sobre todo, por su carácter integrador, utilizado por los virreyes para premiar a criados y deudos, así como para conectar y negociar con los miembros de las élites locales, al tiempo que se convertía para sus miembros en un espacio de promoción, al amparo de los lugartenientes del rey. Por otra parte, la capilla conectaba, a través de los predicadores y, eventualmente, de los confesores de la familia real, con las corporaciones eclesiásticas limeñas, particularmente con los conventos recoletos, promotores y difusores de una espiritualidad del recogimiento ${ }^{58}$.

A través de celebraciones políticas y religiosas, las capitales virreinales se insertaban simbólicamente en la monarquía de los Habsburgo que, como ocurría en otros rincones del imperio, transmitían una imagen jerárquica y ordenada del poder político-religioso y de la sociedad, contribuyendo, al mismo tiempo, a su definición identitaria dentro del mundo hispánico ${ }^{59}$. En aquellas ceremonias, el clero que rodeaba al virrey ocupaba un lugar destacado y, especialmente, su capellán mayor ${ }^{60}$.

En ese marco, la actividad del episcopado fue de suma importancia, sobre todo desde los inicios del siglo XVII'61. Los obispos, más allá de cumplir con sus obligaciones de residencia, visita y corrección, prescriptas por el Concilio de

58 NIEVA OCAMPO, Guillermo y GONZÁLEZ FASANI, Ana Mónica. Lima and the ecclesiastic entourage of the viceroys (1600-1650). En: WYHE, Cordula van y HORTAL MUÑOZ, Eloy (dirs.). Religion, politics and ceremony: re-thinking the royal sites, residencies, convents and monasteries of the Hispanic Monarchy during the seventeenth century. Turnhout: Brepols, 2020 [en prensa].

59 OSORIO, Alejandra. La entrada del virrey y el ejercicio de poder en la Lima del siglo XVII. Historia Mexicana. 2006, vol. LV, n. 3, pp. 767-831.

60 Sirva de ejemplo el orden ceremonial seguido en los funerales en honor de la reina Margarita de Austria, en el año 1612: "A las 3 de la tarde ya estaban el arzobispo y los religiosos en la Iglesia Mayor en este orden: S. Domingo, S. Francisco, S Agustín, NS de la Merced, y C. de Jesús. / A las 4 de la tarde están ya juntos enpalacio los que habían de acompaniar a su excelencia y a la misma hora comenzaron a salir (por el orden que le había dado a don Francisco Messia y Sandoval su camarero real y capitán de la guardia). / En la calle estaban los caballeros encomenderos y feudatarios de esta ciudad y de otras del reino; los ministros de la Real Audiencia; el Colegio de San Martín; el colegio Real de San Felipe, el rector y claustro de la real universidad de San marcos, el cabildo de la ciudad con el tesorero y factor, jueces oficiales de la caja real de Lima. / Seguíanle los Reyes de armas, luego el canciller y registro de la real audiencia; el cuerpo de alabarderos de la guardia de su excelencia. Los tres contadores de la contaduría mayor, en hilera. Iba la real audiencia de dos en dos. / Luego el virrey solo, con don Juan Gaitán gentilhombre de su cámara. Detrás de su excelencia en hilera don Rodrigo de Mendoza y Castilla, su sobrino; el doctor don Diego de Avendaño, capellán mayor de la Capilla Real; don Lope de Torres y de Guzmán, caballerizo mayor y don Nicolás de Mendoza, caballero del hábito de Santiago", Relacion delas exequias q el ex.mo s.r D. Iuan de mendoça y luna Marques de Montesclaros, virrei del Piru hizo en la muerte de la Reina Nuestra S. Doña Margarita. Lima, Pedro de Merchán y Calderón, 1613, p. 64. "En un ceremonial en el que la figura regia se conformaba como el centro, asistir a su lado a los oficios confería un protagonismo que se veía realzado por la presencia de lo más granado de la corte, de ahí la minuciosidad con que se estipulan en todas las constituciones y reglamentos la exacta ubicación de todos y cada uno de los miembros dentro de la Capilla". NEGREDO DEL CERRO, Fernando. La capilla de palacio a principios del siglo XVII. Otras formas de poder en el alcázar madrileño. Studia Historica. Historia Moderna. 2006, n. 28, p. 73.

${ }^{6}$ MAZÍN, Óscar. Representaciones del poder episcopal... Op. cit., p. 380. 
Trento ${ }^{62}$, desarrollaron en las Indias, y también en el Tucumán, una actuación que en gran parte sobrepasaba la mera actividad pastoral, garantizando en buena medida la adhesión de las elites locales a la política real63. Oscar Mazín, refiriéndose a los prelados novohispanos, ha señalado oportunamente que,

"...las actividades de los obispos adquieren un sentido nuevo si atendemos a sus relaciones permanentes con el Consejo de Indias. Su título de miembros del Consejo del rey no fue meramente honorífico y tampoco se restringió a su capacidad de acceder directamente al monarca. En consecuencia, su representación en Madrid se vio redimensionada en comparación con otros cuerpos igualmente capaces de contar con procuradores o delegados en la corte [...] Los obispos estaban convencidos de que las catedrales no se "asentarían" sino en la medida que se desmantelara el orden social surgido de la conquista y se consolidaran los avances del arraigo y poblamiento hispánico en los territorios diocesanos"64.

De hecho, los obispos del Tucumán mantuvieron una asidua correspondencia con Madrid, proporcionando informes detallados de la situación política y militar de la gobernación, y aportando consejos para la solución de problemas políticos. También referían sobre las actividades realizadas en defensa de los indios y de los intereses locales contra el abuso de los gobernadores y de otros potentados. Pero, sobre todo, manifestaban su lealtad al monarca, como muestra de "real servicio", y colaborando también en la promoción de la imagen piadosa de la dinastía. Asimismo, actuaron como mediadores ante el rey para obtener la recompensa a los criollos por servicios a la Corona. Algunas de esas cartas pueden ser consideradas verdaderos memoriales y arbitrios en favor de una mayor participación de los tucumanos en el gobierno de la región y que, en definitiva, ponían en valor una identidad local integrada en el marco plural de la monarquía de los Austrias ${ }^{65}$. En este sentido, hay que recordar que a mediados del siglo XVII aparecen las primeras menciones del Tucumán como "patria" local.

Asegurar la autoridad del rey, de quien era su 'vasallo natural', es la clave de lectura de la actividad de los obispos del XVII66. Melchor Maldonado de Saavedra, que en toda su correspondencia se titula "Obispo del Tucumán, del Consejo de Su

62 TELECHEA IDÍGORAS, José. El obispo ideal según el Concilio de Trento. En: MOZZARELLI, Cesare y ZARDIN, Danilo (ed.). I tempi del Concilio: Religione, cultura e società nell'Europa tridentina. Roma: Bulzoni, 1997, pp. 207-223.

63 SUÁREZ, Margarita (ed.). Parientes, criados y allegados: los vínculos personales en el mundo virreinal peruano. Lima: PUCP-Instituto Riva-Agüero, 2017; MAYER, Alicia y PUENTE BRUNKE, José de la (eds.). Iglesia y Sociedad en la Nueva España y el Perú. Lima: Anacleta, 2015; ÁLVAREZ DE TOLEDO, Cayetana. Juan de Palafox, obispo y virrey. Madrid: Marcial Pons, 2011.

${ }^{64}$ MAZÍN, Óscar. Representaciones del poder episcopal... Op. cit.

65 NIEVA OCAMPO, Guillermo y GONZÁLEZ FASANI, Ana Mónica. Clero y sociedad en el siglo XVII. En: NIEVA OCAMPO, Guillermo [et. al]. La antigua gobernación... Op. cit., pp. 295-350.

${ }^{66}$ El que los eclesiásticos fuesen 'vasallos por naturaleza' del Rey Católico, era el tema central de un debate urticante entre Madrid y Roma durante esos años. Debate que también dividía las mismas filas del clero, sobre todo por la presión financiera que ejercía la Corona sobre la Iglesia y sus bienes. El tema ha sido estudiado por FORTEA PÉREZ, José Ignacio. Olivares y la contribución del clero en la monarquía católica: la décima de 1632. Pedralbes: revista d'historia moderna. 2008, n. 28, pp. 3184. 
Majestad"67, lo expresaba en 1634 del siguiente modo:

"Voy a mi yglesia a cumplir mi obligación y buscando ocasiones en que servir a su magestad siendo exemplo a otros para que hagan lo mismo y en orden a esto no perdonaré a mi vida ni hazienda todo lo pongo a los pies de Vuestra Excelencia para que disponga como fuere servido"68.

En los candidatos al episcopado tucumano durante el siglo XVII, se advierten las mismas condiciones para su elección que en los peninsulares ${ }^{69}$. A saber, debían contar con un importante capital relacional, financiado por dos fuentes principales: su propia familia y su condición de colegiales. Ambas características les hacían contar con importantes valedores en la corte, que es donde, como se ha visto, se fraguaban los nombramientos episcopales, de tal modo que podían ser recomendados ante los confesores reales o los miembros de la Cámara de Castilla o el Consejo de Indias, instancias implicadas en las provisiones episcopales ${ }^{70}$. Por otro lado, la preferencia de religiosos, y no de miembros del clero secular, para el gobierno de las diócesis indianas fue una norma general observada hasta mediados del siglo XVII, en consideración a que se trataba de reputados pastores y predicadores -lo cual los hacía aptos para asumir el gobierno de jurisdicciones con grandes necesidades de orientación teológica- y cuyo perfil concordaba con el "modelo tridentino" ${ }^{71}$. De todos modos, en la segunda mitad del siglo se observa una mayor participación de la corte virreinal limeña en la elección de los obispos y, en consecuencia, de los cuatro prelados que ocuparon la sede tucumana, tres de ellos pertenecían al clero peruano $^{72}$. Al mismo tiempo, los miembros del cabildo eclesiástico, que también debían ser designados por el rey, habían sido individuos foráneos a la diócesis,

67 NIEVA OCAMPO, Guillermo. Vasallo del rey y pastor de su Iglesia: Melchor Maldonado de Saavedra, obispo del Tucumán (1632-1661). En: NIEVA OCAMPO, Guillermo; GONZÁLEZ CUERVA, Rubén y NAVARRO, Andrea (coords.). El príncipe, la corte y sus reinos. Agentes y prácticas de gobierno en el mundo hispano (ss. XIV-XVIII). San Miguel de Tucumán: UNT, 2016, pp. 315-364.

${ }_{68}$ Carta del obispo de Tucumán al presidente del Consejo de Indias, Portobelo, 18 de octubre de 1632. LEVILLIER, Roberto. Papeles Eclesiásticos del Tucumán. Vol. II. Madrid: Imprenta de Juan Pueyo, 1926, pp. 11-12.

${ }^{69}$ Sobre el mecanismo de elección, promoción y designación de obispos durante el siglo XVII véase, DOMÍNGUEZ ORTIZ, Antonio. La sociedad española en el siglo XVII, II, El estamento eclesiástico. Madrid: CSIC, 1992, pp. 19-27; ARVIZU, Fernando de. Criterios para la provisión de sedes episcopales en Indias (1651-1675). Anuario de historia del derecho español. 2007, n. 78-79, pp. 4976.

70 IRIGOYEN LÓPEZ, Antonio. Un obispado para la familia: Francisco Verdín Molina, prelado de Guadalajara y Valladolid en la segunda mitad del siglo XVII. Historia Mexicana. 2008, vol. LVIII, n. 2, p. 568.

71 Situación que durante el reinado de Felipe IV parece que se extendió a la misma península, a causa de la estrecha vinculación de patrocinio entre Corona y órdenes religiosas. Sobre el tema véase, RAWLINGS, Helen. Las órdenes religiosas y la crisis en el nombramiento de obispos en Castilla bajo Felipe IV (1621-1665). Manuscrits. Revista d'Història Moderna [en línea]. 2012, n. 30, pp. 125-137. [Consulta: 22-07-2020]. Disponible en <https://revistes.uab.cat/manuscrits/article/view/v30rawling>; FERNÁNDEZ TERRICABRAS, Ignasi. Al servicio del rey y de la iglesia: El control del episcopado castellano por la Corona en tiempos de Felipe II. En: GUILLAMÓN ÁLVAREZ, Francisco y RUÍZ IBÁÑEZ, José Javier. Lo conflictivo y lo consensual... Op. cit., pp. 205-232.

72 NIEVA OCAMPO, Guillermo y CHILIGUAY, Alejandro. El clero del Tucumán durante el reinado de Carlos II. En: MARTÍNEZ MILLÁN, José; LABRADOR ARROYO, Félix y VALIDO-VIEGAS DE PAULA-SOARES, Filipa (eds.). ¿Decadencia o reconfiguración? Las monarquías de España y Portugal en el cambio de siglo (1640-1724). Madrid: Polifemo, 2017, pp. 525-560. 
mientras que a finales del siglo XVII todas las dignidades eran naturales de la tierra y se habían educado en el colegio y en la universidad de los jesuitas de Córdoba.

\subsection{Jesuitas y monjas como actores políticos}

Los jesuitas se habían instalado en la diócesis a finales del siglo XVI y fundaron la provincia del Paraguay, Tucumán y Río de la Plata en 1609, con casa provincial en Córdoba $^{73}$. Los miembros de la Compañía de Jesús fueron los clérigos más poderosos de la región, puesto que crearon fuertes vinculaciones con las elites locales, a partir de su labor pastoral, asistencial, educativa e incluso por la aceptación de jóvenes tucumanos entre sus filas, beneficiando, de este modo, a sus familias con la condición de limpieza de sangre, aun cuando muchas veces esos novicios habían sido hijos ilegítimos. Por otro lado, se transformaron en agentes de evangelización y, al mismo tiempo, en promotores de la autoridad episcopal en regiones alejadas de los centros de gobierno. Por esos motivos, sus colegios, con filiales en casi todas las ciudades de la gobernación, actuaban como centros de integración de las elites, donde se creaban amistades y se compartía una misma cultura espiritual y política ${ }^{74}$. Una cuestión que merece ser destacada es la transformación que tuvo el carácter de la Compañía en la segunda mitad del siglo $\mathrm{XVII}$, es decir, cuando sus superiores encararon un programa para dotar a sus iglesias y demás emprendimientos en edificaciones monumentales y con mayor adorno, aspecto que significó un mayor gasto. En este sentido, debieron promover la transformación de sus estancias y fincas en verdaderas empresas productoras de recursos para el consumo local y para la venta en las regiones mineras altoperuanas, asociándose de ese modo a los grandes mercaderes y ganaderos locales. Estas cuestiones merecen un mayor estudio, a raíz de la notable influencia que desarrollaron en los cabildos seculares locales y también por el cambio, ya mencionado, que se observa en el perfil de los jesuitas de finales de siglo, mucho más atentos a los negocios en ese periodo ${ }^{75}$.

Una mención especial merece los monasterios de monjas, que actuaron como activas unidades de crédito en todo el virreinato peruano, pero que también sirvieron como espacios de integración de las elites locales. En el Tucumán solo hubo dos conventos femeninos que se fundaron en Córdoba: el de Santa Catalina (1613) y el de San José (1628). Ambos reunieron a jóvenes de las principales familias de la gobernación, puesto que solamente admitían a hijas o descendientes de conquistadores $^{76}$. Por otro lado, su misma existencia, frente a las reiteradas

\footnotetext{
73 Un estudio clásico sobre la actuación de la Compañía de Jesús en Córdoba es el de GRACIA, Joaquín. Los Jesuitas en Córdoba. Buenos Aires: Espasa-Calpe, 1940.

74 NIEVA OCAMPO, Guillermo. Cimentar las identidades locales: los jesuitas y las elites sociales del Tucumán (1600-1650). En: MARTÍNEZ MILLÁN, José; PIZARRO LLORENTE, Henar y JIMÉNEZ PABLO, Ester (coords.). Jesuitas: religión, política y educación (ss. XVI-XVIII). T. III. Madrid: Polifemo, 2012, pp. 1399-1418.

${ }^{75}$ QUARLERI, Lía. Autonomía y buen gobierno. Conflictos internos de la orden jesuita en la provincia del Paraguay (Córdoba y La Rioja, 1680-1720). Cuadernos de Historia, Serie Ec. y Soc. 2005, n. 5, pp. 153-186.

76 NIEVA OCAMPO, Guillermo. Mujeres de clausura: identidad social y recambio generacional entre las dominicas de Córdoba del Tucumán (1613-1750). Archivo Dominicano. 2008, n. 28, pp. 263-305; Crisis económica e identidad religiosa de un monasterio femenino en época de los Austrias: Santa Catalina de Córdoba del Tucumán (1613-1700). Hispania Sacra. 2008, vol. LX, n. 122, pp. 423-443;
} 
negativas de los monarcas de autorizar fundaciones de este tipo en Buenos Aires o en Paraguay, es una muestra de las jerarquías que se establecían, desde Madrid, entre las gobernaciones del sur peruano.

\subsection{Una reflexión historiográfica}

A partir de la década de 1980, en Argentina se introdujeron nuevas perspectivas y métodos para el estudio de la Iglesia Católica, es decir, el clero - secular y regular -, y los laicos. Desde ese entonces comenzaron a ser valorados como objetos de estudio en el campo académico y fueron analizados desde una lógica que no solo se ceñía a la religión. Anteriormente hubo trabajos desde el ámbito confesional principalmente, sobre todo las investigaciones previas a la renovación. En este sentido, una obra de referencia obligatoria es la de Cayetano Bruno, Historia de la Iglesia en Argentina, editada en doce volúmenes entre los años 1966 y 1981, que cubre desde la conquista hasta $1900^{77}$. Existen, además, otras dos obras generales que abarcan desde el siglo XVI y que atraviesan hasta el XX: por un lado, podemos mencionar el trabajo colectivo de la Comisión para el estudio de la Historia de la Iglesia en América Latina Y el Caribe (CEHILA), producida en la década de 1980 y que en ella se expresa un interés por 'ampliar' el concepto de religión; y, por el otro, el volumen de Roberto Di Stefano y Loris Zanatta, escrito desde una perspectiva 'laica', publicado en 2000 y reimpreso en 2009 con un nuevo prólogo y un apéndice de actualización bibliográfica ${ }^{78}$.

Dentro de los estudios particulares se destacaron los que se enfocaron en el siglo XVIII y $\mathrm{XIX}^{79}$, apenas explorado el siglo XVII80, además, la mayoría son de

GONZÁLEZ FASANI, Ana Mónica. Mujeres del infinito. Las carmelitas descalzas en la Córdoba colonial. Bahía Blanca: Ediuns, 2019.

77 BRUNO, Cayetano. Historia de la Iglesia en Argentina. Buenos Aires: Editorial Don Bosco, 19661978. 12 tomos. Otra obra muy importante sobre el periodo: TOSCANO, Julián. El Primitivo Obispado del Tucumán y la Iglesia de Salta. T. I. Buenos Aires: Imprenta M. Biedma, 1937.

78 DUSSEL, Enrique. Historia general de la iglesia en América Latina. introducción a la historia de la iglesia en América Latina. T. I [en línea]. Salamanca: CEHILA. 1983. [Consultado: 04-07-2020]. Disponible en <http://bibliotecavirtual.clacso.org.ar/clacso/otros/20120215104509/iglesia2.pdf>.; DI STEFANO, Roberto y ZANATTA, Loris. Historia de la Iglesia en Argentina: desde la conquista hasta fines del siglo XX. $2^{\mathrm{a}}$ ed. Buenos Aires: Sudamericana, 2009.

79 Sobre el clero tucumano del siglo XVIII desde una perspectiva política, véase: CHILIGUAY, Alejandro. Acefalía episcopal y relajamiento disciplinar. El clero tucumano durante la sede vacante de 1704-1715. Épocas. Revista de Historia [en línea]. 2018, n. 17, pp. 43-58. [Consulta: 23-07-2020]. Disponible en <https://p3.usal.edu.ar/index.php/epocas/article/view/4769>; CHILIGUAY, Alejandro. Los obispos del Tucumán y la corrección de costumbres en los monasterios de Santa Catalina de Siena y San José de Córdoba (1724-1740). Itinerantes. Revista de Historia y Religión [en línea]. 2018, n. 9, pp. 103-121. [Consulta: 20-07-2020]. Disponible en $<$ https://repositoriosdigitales.mincyt.gob.ar/vufind/Record/CONICETDig 7a7faf2f2464662182b538361 8efd996>; CHILIGUAY, Alejandro. Gobernar con celo la diósesis como servidor de Dios y como fiel vasallo de Su Majestad: José Antonio Gutiérrez de Ceballos, obispo del Tucumán (1733-1740). La enseñanza de las Humanidades y las Ciencias Sociales a través del mundo digital. Madrid: Ediciones Digitales, 2017, pp. 195-218; NIEVA OCAMPO, Guillermo. El obispo, el Síndico y la Priora: el reformismo Borbónico y el Monasterio de Santa Catalina de Córdoba del Tucumán (1780-1810). Archivo Dominicano. 2011, n. 32, pp. 53-91. Un trabajo que vincula religiosidad y poder, véase: CARETTA, Gabriela y ZACA, Isabel. "Benditos ancestros": Comunidad, poder y cofradía en Humahuaca en el siglo XVIII. Boletín Americanista. 2011, vol. 1, n. 62, pp. 51-72. Algunos trabajos sobre el siglo XIX: FOLQUER, FOLQUER, Cynthia. Viajeras hacia el fondo del alma. Sociabilidad, 
corte más bien social y económico en detrimento de la historia de la Iglesia con un enfoque político. Y, para complejizar más el asunto, los estudios sobre los ejes políticos se enfocaron en la transición del llamado antiguo régimen al nuevo régimen, el proceso independentista y la configuración de la Iglesia nacional (un ejemplo es el abordaje sobre el clero patriota) ${ }^{81}$.

El análisis de estos temas merece que nos formulemos nuevas preguntas, que respondan a los nuevos métodos, con el fin de observar el papel que tuvo el clero, regular y secular, femenino y masculino, en la cultura política del siglo XVII. Lejos de realizar una biografía colectiva de estos personajes, resultaría más relevante analizar la particularidad de sus carreras y su participación en el ámbito 'civil' y político, pero como gestores y hacedores de ello.

\section{Repositorios y Fuentes}

Aquí nos interesa sobremanera subrayar que existe una vasta documentación de alto valor para poder estudiar este funcionamiento político y eclesiástico del virreinato peruano y del Tucumán. En cuanto a las fuentes manuscritas, hay varias que se conservan en los siguientes repositorios: Archivo Histórico Nacional (Madrid), Archivo General de Indias (con una gran cantidad digitalizada), Archivo Histórico Nacional (Perú), Archivo y Bibliotecas Nacionales de Bolivia (Sucre); todos ellos muy bien administrados y catalogados. Por su parte, en los Archivos Históricos Provinciales de nuestro país, destacándose sobre los demás, el de Córdoba, encontramos la documentación referida a la vida comunal (documentos institucionales y privados). Otro repositorio local importante es el Archivo Municipal de Córdoba, donde se pueden consultar las Actas Capitulares del cabildo secular que no fueron transcriptas y publicadas ${ }^{82}$. Este Archivo presta asesoramiento en sala

\footnotetext{
política y religiosidad en las Dominicas de Tucumán, 1886-1910 [tesis doctoral]. Universidad de Barcelona, 2012. [Consulta: 15-07-2020]. Disponible en $<$ https://www.tdx.cat/handle/10803/96263\#page=1>; SANTOS LEPERA, Lucía y FOLQUER, Cynthia (coords.). Las comunidades religiosas, entre la política y la sociedad. Colección Historias temáticas de Tucumán, siglo XIX y XX. Ediciones Imago Mundi, 2017.

80 Algunos ejemplos son: ESTRUCH, Dolores. Fundar, gobernar y rezar: Una aproximación a los vínculos entre sociedad, política y religión en el Jujuy colonial (1656-1776). RUNA. 2009, vol. 1, pp. 61-78; CARRASCO, Daniela. Vir gravis et prudens et in negotiis magni momenti expertus, magnus concionator: Julián de Cortázar al servicio de Dios y del rey en el Tucumán (1616-1621). RHPT Revista Historia para Todos. 2015, n. 1, año 1, pp. 54-64.

${ }^{81}$ Algunos aspectos del Tucumán referidos a las prácticas religiosas en el siglo XVIII y XIX, pueden verse estas obras generales: AYROLO, Valentina; BARRAL, María Elena y DI STEFANO, Roberto (coords.). Catolicismo y secularización. Argentina, primera mitad del siglo XIX. Buenos Aires: Biblos, 2012; Sobre algunas ciudades específicas del antiguo Tucumán en el siglo XIX: AYROLO, Valentina y MAZZONI, Silvia. De familiar a Obispo de Córdoba. La trayectoria política de Benito Lascano como ejemplo de ascenso en la carrera eclesiástica, 1800-1836. Anuario de la Escuela de Historia Virtual. 2013, n. 4, pp. 35-56.

82 Las Actas Capitulares de Córdoba son documentos muy valiosos ya que fueron elaboradas por los cabildantes y testimonian los acontecimientos de la ciudad desde su fundación hasta 1823. Las Actas de las últimas décadas del siglo XVII nunca fueron publicadas, sí las de 1573 hasta 1671 (Libro I, II, III, IV, V, VI, VII, VIII, IX, X y XI). Los libros II al VIII fueron publicados en una sola edición, que inició en 1880 y finalizó en 1884. Los libros I, IX, X y XI, se publicaron por segunda vez en 1974, 1952, 1953, 1954, respectivamente. Además del Archivo Histórico Municipal, en el ex Instituto de Estudios Americanistas, fondo documental "Monseñor Pablo Cabrera", pueden consultarse los documentos
} 
para el manejo de inventarios, índices y catálogos. Hay que decir que hubo documentos que se trasladaron al Archivo Histórico Provincial, sobre todo por la falta de espacio y mobiliario específico para el mantenimiento y conservación de los que datan de fechas muy tempranas. No obstante, las Actas Capitulares se encuentran abiertas a la consulta del público a través de un aparato de lectura de microfilms.

En cuanto a las fuentes editadas, podemos citar los trabajos que realizaron Levillier, Larrouy ${ }^{83}$ y Freyre. Indudablemente, el que se destaca es el primero, ya que ha publicado en varios tomos las Cartas y Papeles de los Gobernantes del Perú, donde transcribió: la correspondencia de los virreyes del Perú, de los gobernadores del Río de la Plata, el Tucumán y Paraguay, los juicios de residencia, las relaciones de visitadores, y las probanzas de méritos y servicios de los descubridores del Tucumán y el Río de la Plata. Asimismo, en la obra titulada Audiencia de Charcas, Levillier transcribió las cartas de los presidentes y oidores de dicha Audiencia con miembros de: la Audiencia de Lima, la primera Audiencia de Buenos Aires, el Consejo de Indias, los Cabildos seculares del Río de la Plata, Paraguay y Tucumán, y con los mismos reyes españoles ${ }^{84}$. En suma, hay un número, ya considerable, de publicaciones americanas y españolas, donde se dan a luz papeles inéditos, gracias a los cuales la impropiamente llamada historia colonial hispánica va conociéndose con mayor exactitud.

Por otro lado, debemos mencionar que existe una cierta dificultad para acceder a la documentación clerical de esta época. En el caso particular de Argentina, el problema se debe a la ausencia de un repositorio de excepcional importancia como lo fuera el Archivo de la Curia Metropolitana de Buenos Aires, ya que fue quemado en 1955. Solo es posible disponer de algunos estudios realizados previamente con dichos documentos. Y en el caso de los archivos del resto de las provincias del país, en su gran mayoría se encuentran directamente cerrados a los estudiosos. Algunos accesos a esos repositorios dependen de circunstancias impredecibles, como la buena voluntad del obispo, del superior o del archivero, figura que, en muchos casos, ni siquiera existe.

Un repositorio de consulta obligatoria para los estudiosos de la diócesis del Tucumán, accesible y bien organizado, es el Archivo del Arzobispado de Córdoba. Tras el traslado de la sede episcopal de la ciudad de Santiago del Estero a Córdoba en 1699, toda la documentación relativa al obispado quedó resguardado en dicho repositorio. La densidad documental disponible aún ofrece posibilidades a los

editados en libros de modo autónomos y privados, y mediante microfilms en el Archivo del Arzobispado de Córdoba.

83 Larrouy ofrece una guía de documentos que pueden encontrarse en los Archivos de Córdoba y Tucumán: LARROUY, Antonio. Los Archivos de Córdoba y Tucumán. Informe del Comisionado. Buenos Aires: Imprenta de Juan A. Alsina, 1909.

84 LARROUY, Antonio. Documentos del Archivo de Indias para la Historia del Tucumán. T. I. Madrid: L. J. Rosso y Cía. Impresores, 1927; FREYRE, Ricardo. El Tucumán Colonial. Documentos y mapas del archivo de Indias. Buenos Aires: Coni Hermanos, 1915. LEVILLIER, Roberto. La Audiencia de Charcas. Correspondencia de presidentes y Oidores. T. I-III. Madrid: Imprenta de Juan Pueyo, 19181922; LEVILLIER, Roberto. Los gobernantes del Perú. Madrid: Sucesores de Rivadaneyra-Imprenta de Juan Pueyo, 1921-1926. 14 tomos; LEVILLIER, Roberto. Gobernación del Tucumán. Papeles de gobernadores. Madrid: Imprenta de Juan Pueyo, 1920. 
investigadores de desarrollar temas relativos a la Iglesia tucumana que todavía no han sido explotadas plenamente ${ }^{85}$.

Por otra parte, actualmente encontramos documentos que se han puesto al alcance de los investigadores mediante transcripciones en ediciones cuidadas, por ejemplo: la publicación de las Actas del Cabildo Eclesiástico del Obispado del Tucumán con sede en Santiago del Estero, entre 1592 a 1667, editada por Silvia Palomeque y un grupo de investigadores de la Universidad Nacional de Córdoba ${ }^{86}$; los dos tomos de los Papeles Eclesiásticos de Levillier; Las Relaciones Ad Limina; los tomos de las cartas Anuas de los Jesuitas; entre otros.

\section{Bibliografía}

ÁLVAREZ DE TOLEDO, Cayetana. Juan de Palafox, obispo y virrey. Madrid: Marcial Pons, 2011.

AMADORI, Arrigo. No es menos servicio el diferir que el ejecutar: el programa fiscal de Felipe IV para el Perú y la gestión del virrey Chinchón (1629-1641). Historia. 2013, n. 46, pp. 7-37.

AMADORI, Arrigo. Negociando la obediencia. Gestión y reforma de los virreinatos americanos en tiempos del conde-duque de Olivares (1621-1643). Madrid: CSIC-Universidad de Sevilla, 2013.

ANELLO, Alejandra; DOUCET, Gastón y PALOMEQUE, Silvia. Los pueblos de indios del Tucumán colonial: pervivencia y desestructuración. Jujuy: Universidad Nacional de Jujuy, 2002.

ARAMENDI, Bárbara ¿Poder local versus poder real? Conflictos entre el Cabildo de Córdoba y el Gobernador don Joaquín Espinosa y Dávalos. Andes [en línea]. 2011, vol. 22 [Consulta: 20-10-2018] Disponible en: $<$ https://www.redalyc.org/pdf/127/12719967003.pdf>.

ARANA, Margarita. Enfrentamientos en el Cabildo entre miembros de la elite de San Miguel de Tucumán en 1654: la elección del teniente de gobernador. Andes.

\footnotetext{
85 Un ejemplo del "redescubrimiento" de las fuentes disponibles en este repositorio son los estudios de de Federico Sartori sobre la inquisición en Córdoba y el ya citado de Clarisa Pedrotti sobre la música. Véase: SARTORI MOYANO, Federico Tulio. Al sur de las hogueras. Inquisición y sociedad en Córdoba del Tucumán durante los siglos XVI y XVII. Córdoba: Universidad Nacional de Córdoba, 2020; PEDROTTI, Clarisa. Pobres, negros y esclavos... Op. cit.

86 PALOMEQUE, SILVIA (dir.). Actas del Cabildo eclesiástico. Obispado del Tucumán con sede en Santiago del Estero 1592-1667. Córdoba: Programa de Historia Regional Andina, CIFFyH, UNC, 2005; BARBERO, Santiago; ASTRADA, Estela y CONSIGLI, Julieta. Relaciones ad limina de los obispos de la diósesis del Tucumán (siglos XVII al XIX). Córdoba-Argentina: Prosopis Editora, 1995; LEVILLIER, Roberto. Papeles eclesiásticos... Op. cit.; Cartas Anuas de la Provincia del Paraguay, Chile y Tucumán de la Compañía de Jesús. Obra publicada por la Facultad de Filosofía y Letras, Instituto de Investigaciones. Documentos para la Historia Argentina, tomo XIX y XX, Iglesia. Buenos Aires, 1927-1929. Debemos decir que las Cartas Anuas de la Compañía de Jesús en la Provincia del Paraguay... desde 1608 hasta 1762 y las Cartas de los Padres Generales a los Provinciales, pueden encontrarse en el Archivo Histórico de la Provincia de Buenos Aires "Dr. Ricardo Levene".
} 
2013, vol. 24.

ARVIZU, Fernando de. Criterios para la provisión de sedes episcopales en Indias (1651-1675). Anuario de historia del derecho español. 2007, n. 78-79, pp. 49-76.

AYROLO, Valentina; BARRAL, María Elena y DI STEFANO, Roberto (coords.). Catolicismo y secularización. Argentina, primera mitad del siglo XIX. Buenos Aires: Biblos, 2012.

AYROLO, Valentina y MAZZONI, Silvia. De familiar a Obispo de Córdoba. La trayectoria política de Benito Lascano como ejemplo de ascenso en la carrera eclesiástica, 1800-1836. Anuario de la Escuela de Historia Virtual. 2013, n. 4, pp. 35-56.

AUSTRAND, Françoise (dir.). Prosopographie et genèse de l'état moderne. Paris, 1986.

BAKER, Keith (ed.). The political culture of the Old Regime. Vol. I de la Serie The French Revolution and the creation of modern political culture. Nueva YorkOxford: Pergamon, 1887.

BARBERO, Santiago; ASTRADA, Estela y CONSIGLI, Julieta. Relaciones ad limina de los obispos de la diósesis del Tucumán (siglos XVII al XIX). CórdobaArgentina: Prosopis Editora, 1995.

BARRIERA, Darío. Resistir al teniente con la letra del Rey: la conflictiva relación del cabildo de Santa Fe con la gobernación del Río de la Plata durante los años 1620. En: DALLA CORTE, Gabriela [et. al.] (coords.). Homogeneidad, diferencia y exclusión en América. X Encuentro-Debate América Latina, ayer y hoy. Barcelona: Universitat de Barcelona, 2006, pp. 65-71.

BARRIERA, Darío. Abrir puertas a la tierra. Microanálisis de la construcción de un espacio político. Santa Fe, 1573-1640. Santa Fe: Museo Histórico Provincial Brigadier Estanislao López, 2013.

BENOIST, Pierre. La Monarchie ecclésiale en France. Le Clergé de cour en France à l'époque moderne. Seyssel: Champs Vallon, collection Époques, 2013.

BERNARD, Carmen (comp.). Descubrimiento, conquista y colonización de América a quinientos años, México: Fondo de Cultura Económica, 1994.

BERTRAND, Michel. Poder peleado, poder compartido: familias y Estado en la América española colonial. En: MOLINA PUCHE, Sebastián e IRIGOYEN LÓPEZ, Antonio (ed.). Territorios distantes, comportamientos similares. Familias, redes y reproducción social en la Monarquía Hispánica (siglos XIV-XIX). Murcia: Edit.UM, 2009, pp. 217-236. 
BRUNO, Cayetano. Historia de la Iglesia en Argentina. Buenos Aires: Editorial Don Bosco, 1966-1978. 12 tomos.

BÜSCHGES, Christian. Del criado al valido. Patronazgo de los virreyes de Nápoles y Nueva España (primera mitad del siglo XVII). En: CANTÚ, Francesca (ed.). Las cortes virreinales de la Monarquía española: América e Italia. Roma: Viella, 2008, pp. 157-181.

BÜSCHGES, Christian. ¿Absolutismo virreinal? La administración del marqués de Gelves revisada (Nueva España, 1621-1624). En: DUBET, Anne y RUIZ IBAÑEZ, José Javier (coords.). Las monarquías española y francesa (siglos XVIXVIII): ¿dos modelos políticos? Madrid: Casa de Velázquez, 2010, pp. 31-44.

CAÑEQUE, Alejandro. Cultura vicerregia y Estado colonial. Una aproximación crítica al estudio de la Historia política de la Nueva España. Historia Mexicana [en línea]. 2001, vol. LI, n. 1, pp.5-57. [Consulta: 04-07-2020]. Disponible en: $<$ https://www.redalyc.org/pdf/600/60051101.pdf>.

CAÑEQUE, Alejandro. The King's Living Image: The Culture and Politics of Viceregal Power in Colonial Mexico. Nueva York: Routledge, 2004.

CARDIM, Pedro y PALOS, Joan-Lluis (eds.). El mundo de los virreyes en las Monarquías de España y Portugal. Madrid: Iberoamericana, 2012.

CARETTA, Gabriela y ZACA, Isabel. "Benditos ancestros": Comunidad, poder y cofradía en Humahuaca en el siglo XVIII. Boletín Americanista. 2011, vol. 1, n. 62, pp. 51-72.

CARMIGNANI, Leticia. 'Soy en esta provincia muy odiado de los vecinos encomenderos'. El gobernador del Tucumán Alonso de Ribera y su proyecto Político (1605-1611). Memoria Americana [en línea]. 2005, vol. 23, n. 1, pp. 1138. [Consulta: 15-10-2018] Disponible en: $<$ http://ppct.caicyt.gov.ar/index.php/memoria-americana/article/view/5862/6183>.

CARRASCO, Daniela. Vir gravis et prudens et in negotiis magni momenti expertus, magnus concionator: Julián de Cortázar al servicio de Dios y del rey en el Tucumán (1616-1621). RHPT Revista Historia para Todos. 2015, n. 1, año 1, pp. 54-64.

CARRASCO, Daniela. Conflictos de poder en el Tucumán Hispano: el gobernador Alonso de Ribera y el obispo Hernando de Trejo y Sanabria. Libros de la corte [en línea]. 2018, n. 16, año 10, pp. 8-25. [Consulta: 20-07-2020] Disponible en: <https://revistas.uam.es/librosdelacorte/article/view/9612>.

CASTRO OLAÑETA, Isabel. 'Vuestra Magestad se sirva de ordenar al Governador, que no apriete en las ordenanzas del visitador'. Gobierno colonial y poder local en la Gobernación del Tucumán (1603-1619). Bibliographica Americana. 2013, n. 9, pp 23-48. 
CASTRO OLAÑETA, Isabel. "Donde están situados los mas yndios de la jurisdiccion desta ciudad". Un acercamiento etnohistórico a las encomiendas y pueblos de indios del Río Salado. Santiago del Estero entre fines del siglo XVI y principios del siglo XVII. Surandino monográfico [en línea]. 2013, vol. 3. [Consulta: 25-082020] <http://revistascientificas.filo.uba.ar/index.php/surandino/article/view/477>.

CHILIGUAY, Alejandro. Gobernar con celo la diósesis como servidor de Dios y como fiel vasallo de Su Majestad: José Antonio Gutiérrez de Ceballos, obispo del Tucumán (1733-1740). La enseñanza de las Humanidades y las Ciencias Sociales a través del mundo digital. Madrid: Ediciones Digitales, 2017, pp. 195218.

CHILIGUAY, Alejandro. Acefalía episcopal y relajamiento disciplinar. El clero tucumano durante la sede vacante de 1704-1715. Épocas. Revista de Historia [en línea]. 2018, n. 17, pp. 43-58. [Consulta: 23-07-2020]. Disponible en <https://p3.usal.edu.ar/index.php/epocas/article/view/4769>.

CHILIGUAY, Alejandro. Los obispos del Tucumán y la corrección de costumbres en los monasterios de Santa Catalina de Siena y San José de Córdoba (17241740). Itinerantes. Revista de Historia y Religión [en línea]. 2018, n. 9, pp. 103121. [Consulta: 20-07-2020]. Disponible en $<$ https://repositoriosdigitales.mincyt.gob.ar/vufind/Record/CONICETDig 7a7faf2f 2464662182b5383618efd996>.

COLLINO, Fernando. Un teniente de gobernador de Corrientes en el temprano S. XVII. Revista Escuela de Historia. 2016, vol. 15, n. 2.

COROLEU, José y ARANDA, Manuel. América: historia de su colonización, dominación é independencia. Vol. 4. Montaner y Simón, 1896.

DE NARDI, Loris. Los virreinatos de Ssicilia y Perú en el siglo XVII. Apuntes sobre una comparación en el marco de la historia global de dos realidades solo geográficamente lejanas. Estudios políticos [en línea]. 2014, n. 45, pp. 55-75. [Consulta: 04-07-2020]. Disponible en $<$ http://www.scielo.org.co/scielo.php?script=sci abstract\&pid=S01215167201400 0200004\&lng=es\&nrm=iso\&tlng=es $>$.

DI STEFANO, Roberto y ZANATTA, Loris. Historia de la Iglesia en Argentina: desde la conquista hasta fines del siglo XX. 2ª ed. Buenos Aires: Sudamericana, 2009.

DOMíNGUEZ ORTIZ, Antonio. La sociedad española en el siglo XVII, II, El estamento eclesiástico. Madrid: CSIC, 1992.

DOUCET, Gastón. En torno a la población aborigen y a las encomiendas de indios del antiguo Tucumán. Revista de Indias. 1987, vol. 179, n. 47, pp. 253-313.

DUSSEL, Enrique. Historia general de la iglesia en América Latina. introducción a la historia de la iglesia en América Latina. T. I [en línea]. Salamanca: CEHILA. 
1983. [Consultado: 04-07-2020]. Disponible en $<$ http://bibliotecavirtual.clacso.org.ar/clacso/otros/20120215104509/iglesia2.pdf>.

ELLIOTT, John. Europe of composite monarchies. Past and Present. 1992, vol. 137, n. 1 , pp. $48-71$.

ESTEBAN ESTRÍNGANA, Alicia. Servir al Rey en la Monarquía de los Austrias. Medios, fines y logros del servicio al soberano en los siglos XVI y XVII. Madrid: Sílex ediciones S.L., 2012.

ESTRUCH, Dolores. Fundar, gobernar y rezar: Una aproximación a los vínculos entre sociedad, política y religión en el Jujuy colonial (1656-1776). RUNA. 2009, vol. 1, pp. 61-78

FARBERMAN, Judith y BOIXADÓS, Roxana. Sociedades indígenas y encomienda en el Tucumán colonial. Un análisis comparado de la visita de Luján de Vargas. Revista de Indias. 2006, vol. LXVI, n. 238.

FERNÁNDEZ ALBALADEJO, Pablo. La historia política: de una encrucijada a otra. En: LÓPEZ, Roberto y LOPO GONZÁLEZ, Domingo (eds.). Balance de la historiografía modernista, 1973-2001. Homenaje al Profesor Dr. Antonio Eiras Roel. Santiago de Compostela: Xunta de Galicia, 2003, pp. 479-488.

FERNÁNDEZ TERRICABRAS, Ignasi. Al servicio del rey y de la iglesia: El control del episcopado castellano por la Corona en tiempos de Felipe II. En: GUILLAMÓN ÁLVAREZ, Francisco y RUÍZ IBÁÑEZ, José Javier. Lo conflictivo y lo consensual en Castilla: sociedad y poder político, 1521-1715: homenaje a Francisco Tomás y Valiente. Murcia: Universidad de Murcia, 2001, pp. 205-232.

FERREIRO, Juan Pablo. Todo queda en familia... política y parentesco entre las familias notables del Jujuy del XVII. En: Beneméritos, aristócratas y empresarios: identidades y estructuras sociales de las capas altas urbanas en América Hispánica. Frankfurt-Madrid: Ververt, Verlagsgesellschafl, 1999.

FRADKIN, Raúl y GARAVAGLIA, Juan. La Argentina colonial. Buenos Aires: Siglo XXI, 2009.

FREYRE, Ricardo. Historia de la República del Tucumán. Buenos Aires: Imprenta y Editora de Coni Hermanos, 1911.

FREYRE, Ricardo. El Tucumán Colonial. Documentos y mapas del archivo de Indias. Buenos Aires: Coni Hermanos, 1915

FREYRE, Ricardo. El Tucumán del siglo XVI. Bajo el gobierno de Juan de Ramírez de Velasco. Buenos Aires: Imprenta y Editora de Coni Hermanos, 1915.

FOLQUER, Cynthia. Viajeras hacia el fondo del alma. Sociabilidad, política y religiosidad en las Dominicas de Tucumán, 1886-1910 [tesis doctoral]. Universidad de Barcelona, 2012. [Consulta: 15-07-2020]. Disponible en 
<https://www.tdx.cat/handle/10803/96263\#page=1>.

FORTEA PÉREZ, José Ignacio. Olivares y la contribución del clero en la monarquía católica: la décima de 1632. Pedralbes: revista d'historia moderna. 2008, n. 28 , pp. 31-84.

FORTUNY, Pablo. Nueva Historia del Norte Argentino. Buenos Aires: Ediciones Theoría. 1911.

GARCÍA GARCÍA, Bernardo José y CARRERAS ARES, Juan José. La Capilla Real de los Austrias: música y ritual de corte en la Europa Moderna. Madrid: Fundación Carlos de Amberes, 2001.

GARRIGA, Carlos. Orden jurídico y poder político en el Antiguo Régimen. Istor. Revista de historia internacional [en línea]. 2004, vol. 16, pp. 3-44. [Consulta: 2207-2020] <http://www.istor.cide.edu/archivos/num 16/dossier1.pdf>

GILBERT, Felix. Politics or Culture? Reflections on Ranke and Burckhardt. New Jersey: Princeton University Press, 1990.

GIL PUJOL, Xavier. Tiempo de Política: Perspectivas Historiográfica sobre la Europa Moderna. Barcelona: Universitat de Barcelona, Servicio de Publicaciones, 2006.

GINZBURG, Carlo. Microhistoria: dos o tres cosas que sé de ella. Entrepasados. 1995, n. 8, pp. 51-73.

GINZBURG, Carlo. Huellas. Raíces de un paradigma indiciario. Rosario: Tentativas, Prohistoria ediciones, 2004, pp. 69-113.

GONZÁLEZ CUERVA, Rubén. Los virreinatos americanos: imagen, cortes y gestión de la distancia. Libros de la Corte [en línea]. 2017, Monográfico 5, año 9, pp. 926. [Consulta: 20-07-2020] Disponible en < https://revistas.uam.es/librosdelacorte/article/view/7812>.

GONZÁlEZ FASANI, Ana Mónica. Mujeres del infinito. Las carmelitas descalzas en la Córdoba colonial. Bahía Blanca: Ediuns, 2019.

GONZÁLEZ RODRíGUEZ, Adolfo. La encomienda en el Tucumán. Sevilla: Diputación de Sevilla, 1984.

GONZÁLEZ RODRíGUEZ, Adolfo. El cabildo de Córdoba durante el siglo XVI: encomenderos, propietarios de tierras, tratante de negros y comerciantes. Análisis de un grupo de poder. Córdoba: Centro de estudios genealógicos de Córdoba, 1986.

GRACIA, Joaquín. Los Jesuitas en Córdoba. Buenos Aires: Espasa-Calpe, 1940.

GRENDI, Edoardo. Repensar la microhistoria. Entrepasados. 1996, n. 10, pp. 131- 
140.

HEXTER, Jack. Reappraisals in history. Chicago-Londres, 1979.

IRIGOYEN LÓPEZ, Antonio. Un obispado para la familia: Francisco Verdín Molina, prelado de Guadalajara y Valladolid en la segunda mitad del siglo XVII. Historia Mexicana. 2008, vol. LVIII, n. 2, p. 568.

LARROUY, Antonio. Los Archivos de Córdoba y Tucumán. Informe del Comisionado. Buenos Aires: Imprenta de Juan A. Alsina, 1909.

LARROUY, Antonio. Documentos del Archivo de Indias para la Historia del Tucumán. T. I. Madrid: L. J. Rosso y Cía. Impresores, 1927.

LATASA VASALLO, Pilar. La corte virreinal peruana: perspectivas de análisis (siglos XVI y XVII). En: BARRIOS PINTADO, Feliciano (coord.). El gobierno de un mundo: virreinatos y audiencias en la América Hispánica. España: Ediciones de la Universidad de Castilla-La Mancha, 2004, pp. 341-374.

LATASA VASALLO, Pilar. Poder y favor en la corte virreinal del Perú: los criados del marqués de Montesclaros (1607-1615). Histórica (Perú). 2012, vol. 36, n. 2, pp. 49-84.

LE GOFF, Jaques. Comment Écrire une biographie historique aujourd'hui? Le Débat. París: Gallimard. 1989, n. 54, pp. 48-53.

LEVENE, Ricardo. Las Indias no eran colonias. Buenos Aires: Espasa-Calpe, 1951.

LEVI, Giovani. Sobre microhistoria. En: BURKE, Peter (ed.). Formas de hacer historia. Madrid: Alianza, 1993.

LEVILLIER, Ricardo. Chile y el Tucumán en el siglo XVI (el conflicto Villagra-Núñez de Prado): refutación de las inexactitudes del señor don T. Thayer Ojeda en su análisis crítico de la Nueva crónica de la conquista del Tucumán. París: Le livre libre, 1928.

LEVILLIER, Roberto. Gobernación del Tucumán. Papeles de gobernadores. Madrid: Imprenta de Juan Pueyo, 1920.

LEVILLIER, Roberto. Historia Argentina. T. II. Buenos Aires: Plaza y Janes Editores, 1968.

LEVILLIER, Roberto. La Audiencia de Charcas. Correspondencia de presidentes y Oidores. T. I-III. Madrid: Imprenta de Juan Pueyo, 1918-1922.

LEVILLIER, Roberto. Los gobernantes del Perú. Madrid: Sucesores de RivadaneyraImprenta de Juan Pueyo, 1921-1926. 14 tomos. 
LEVILLIER, Roberto. Nueva crónica de la conquista del Tucumán. Vol. I-III. Buenos Aires: Editorial Nosotros, 1926-1931.

LEVILLIER, Roberto. Papeles Eclesiásticos del Tucumán. Vol. II. Madrid: Imprenta de Juan Pueyo, 1926.

LIZONDO BORDA, Manuel. Historia de la Gobernación del Tucumán, siglo XVI. Buenos Aires: Imprenta y Editora de Coni Hermanos, 1928.

LOBOS, Héctor. Conquista y fundaciones del Tucumán y el Río de la Plata. En: Nueva Historia de la Nación Argentina Segunda Parte: La Argentina de los siglos XVII y XVIII. Buenos Aires: Editorial Planeta, 1999.

LORANDI, Ana María. El servicio personal como agente de desestructuración en el Tucumán colonial. Revista Andina. 1988, n. 1, año 6.

LUQUE COLOMBRES, Carlos. Trejo y Córdoba. Córdoba: Dirección general de Publicidad de la Universidad Nacional de Córdoba, 1953.

LUQUE COLOMBRES, Carlos. La diócesis del Tucumán y Córdoba. Córdoba, 1970.

LUQUE COLOMBRES, Carlos. Para la historia de Córdoba. Córdoba: Secretaría y Ministerio de Educación y Cultura, 1971.

LUQUE COLOMBRES, Carlos y CORNEJO, Atilio. Don Gerónimo Luis de Cabrera y Salta. Cuarto centenario de las Fundaciones de Córdoba y Santa Fe (15731973). Buenos Aires: Academia Nacional de la Historia, 1974.

MARCHIONI, Marcelo. Una elite consolidada: el Cabildo de Salta en tiempos de cambios. En: MATA DE LÓPEZ, Sara (comp.) Persistencias y cambios: Salta y el Noroeste argentino. 1770-1840. Rosario: Prohistoria y Manuel Suárez, 1999, pp.177-217.

MARTÍNEZ MILLÁN, José y FERNÁNDEZ CONTI, Santiago (coords.). La Monarquía de Felipe II: La Casa del Rey. Vol. I. Madrid: Fundación Mapfre, 2005.

MARTÍNEZ MILLÁN, José. La corte de la monarquía hispánica. Studia historica. Historia moderna. 2006, n. 28, pp. 17-61.

MARTÍNEZ MILLÁN, José y VICEGLIA, María Antonieta (dirs.). La monarquía de Felipe III: La corte. Vol. I. Madrid: Fundación MAPFRE-Instituto de Cultura, 2008.

MARTÍNEZ MILLÁN, José; GONZÁLEZ CUERVA, Rubén y RIVERO RODRÍGUEZ, Manuel (dirs.). La corte de Felipe IV (1621-1665). Reconfiguración de la Monarquía Católica. Cortes virreinales y gobernaciones americanas. T. IV, vol. IV. Madrid: Polifemo, 2018.

MARWICK, Arthur. The nature history. Londres, 1970. 
MAYER, Alicia y PUENTE BRUNKE, José de la (eds.). Iglesia y Sociedad en la Nueva España y el Perú. Lima: Anacleta, 2015.

MAZíN, Óscar (ed.). Las representaciones del poder en las sociedades hispánicas. México: El Colegio de México-Centro de Estudios Históricos, 2012.

MAZIN, Óscar y RUIZ IBÁÑEZ, José Javier (eds.). Las Indias Occidentales Procesos de incorporación territorial a las Monarquías Ibéricas. México: El Colegio de México, 2012.

NEGREDO DEL CERRO, Fernando. Los predicadores de Felipe IV. Corte, intrigas y religión en la España del Siglo de Oro. Madrid: Actas, 2006.

NEGREDO DEL CERRO, Fernando. La capilla de palacio a principios del siglo XVII. Otras formas de poder en el alcázar madrileño. Studia Historica. Historia Moderna. 2006, n. 28.

NIEVA OCAMPO, Guillermo. Mujeres de clausura: identidad social y recambio generacional entre las dominicas de Córdoba del Tucumán (1613-1750). Archivo Dominicano. 2008, n. 28, pp. 263-305.

NIEVA OCAPMO, Guillermo. Crisis económica e identidad religiosa de un monasterio femenino en época de los Austrias: Santa Catalina de Córdoba del Tucumán (1613-1700). Hispania Sacra. 2008, vol. LX, n. 122, pp. 423-443.

NIEVA OCAMPO, Guillermo. El obispo, el Síndico y la Priora: el reformismo Borbónico y el Monasterio de Santa Catalina de Córdoba del Tucumán (17801810). Archivo Dominicano. 2011, n. 32, pp. 53-91.

NIEVA OCAMPO, Guillermo. Cimentar las identidades locales: los jesuitas y las elites sociales del Tucumán (1600-1650). En: MARTíNEZ MILLÁN, José; PIZARRO LLORENTE, Henar y JIMÉNEZ PABLO, Ester (coords.). Jesuitas: religión, política y educación (ss. XVI-XVIII). T. III. Madrid: Polifemo, 2012, pp. 1399-1418.

NIEVA OCAMPO, Guillermo; GONZÁLEZ CUERVA, Rubén y NAVARRO, Andrea (coords.). El príncipe, la corte y sus reinos. Agentes y prácticas de gobierno en el mundo hispano (ss. XIV-XVIII). San Miguel de Tucumán: UNT, 2016.

NIEVA OCAMPO, Guillermo y CHILIGUAY, Alejandro. El clero del Tucumán durante el reinado de Carlos II. En: MARTíNEZ MILLÁN, José; LABRADOR ARROYO, Félix y VALIDO-VIEGAS DE PAULA-SOARES, Filipa (eds.). ¿Decadencia o reconfiguración? Las monarquías de España y Portugal en el cambio de siglo (1640-1724). Madrid: Polifemo, 2017, pp. 525-560.

NIEVA OCAMPO, Guillermo y CORREA, Marcelo. Agentes de gobierno en la Monarquía Hispana durante el siglo XVII: sujetos, vínculos y prácticas. Libros de la corte [en línea]. 2019, n. 18. [Consulta: 20-07-2020] Disponible en: $<$ https://revistas.uam.es/librosdelacorte/article/view/11082>. 
NIEVA OCAMPO, Guillermo; GONZÁLEZ FASANI, Ana Mónica y CHILIGUAY, Alejandro. La antigua gobernación del Tucumán: política, sociedad y cultura, siglos XVI al XIX. Salta: Milor, 2020.

NIEVA OCAMPO, Guillermo y GONZÁLEZ FASANI, Ana Mónica. Lima and the ecclesiastic entourage of the viceroys (1600-1650). En: WYHE, Cordula van y HORTAL MUÑOZ, Eloy (dirs.). Religion, politics and ceremony: re-thinking the royal sites, residencies, convents and monasteries of the Hispanic Monarchy during the seventeenth century. Turnhout: Brepols, 2020 [en prensa].

NOGALES RINCÓN, David. La representación religiosa de la monarquía castellanoleonesa: la Capilla Real (1252-1504) [tesis doctoral]. Madrid: Universidad Complutense de Madrid, 2009.

OLIVIETO, Guillermina y CASTRO OLAÑETA, Isabel. Entre Charcas y el Tucumán. Las sociedades indígenas frente a los sistemas de dominación desde una perspectiva etnohistórica, siglos XV al XVIII. Memoria Americana. Cuadernos de Etnohistoria [en línea]. 2019, vol. 27, n. 1, pp. 5-10. [Consulta: 20-07-2020]. Disponible en: < http://revistascientificas.filo.uba.ar/index.php/MA/article/view/6329>.

OSORIO, Alejandra. La entrada del virrey y el ejercicio de poder en la Lima del siglo XVII. Historia Mexicana. 2006, vol. LV, n. 3, pp. 767-831.

OSORIO, Alejandra. Inventing Lima: Baroque Modernity in Peru's South Sea Metropolis (The Americas in the early Modern Atlantic world). Reino Unido: Palgrave MacMillan, 2008.

PAGE, Carlos. Las proclamaciones en Córdoba del Tucumán. Revista Computense de Historia de América [en línea]. 2004, vol. 30, pp. 77-94. [Consulta: 19-072020]. Disponible $<$ https://revistas.ucm.es/index.php/RCHA/article/view/RCHA0404110077A/28599 $>$.

PAGE, Carlos. El espacio público en las ciudades Hispanoamericanas. El caso de Córdoba (Argentina), siglos XVI a XVIII. Córdoba: Báez Ediciones, 2008.

PALOMEQUE, SILVIA (dir.). Actas del Cabildo eclesiástico. Obispado del Tucumán con sede en Santiago del Estero 1592-1667. Córdoba: Programa de Historia Regional Andina, CIFFyH, UNC, 2005.

PARDO MOLERO, Juan Francisco y LOMAS CORTÉS, Manuel. Ministros idóneos. El marco del servicio al rey en la Monarquía Hispana. En: Oficiales reales. Los ministros de la Monarquía Católica (siglos XVI y XVII). Valencia, Universidad de Valencia-Red Columnaria, 2012.

PEDROTTI, Clarisa. Pobres, negros y esclavos. Música religiosa en Córdoba del Tucumán (1699-1840). Córdoba: Editorial Brujas, 2017. 
PIETSCHMANN, Horts. El Estado y su evolución al principio de la colonización española de América. México: Fondo de Cultura Económica, 1989.

POCATERRA, Mariana. Instituciones políticos-administrativas de la América Hispana (1492-1810). Madrid: Universidad Complutense de Madrid, 1999.

PONCE LEIVA, Pilar. La argamasa que une los reinos: gestión e integración de las Indias en la Monarquía Hispánica, siglo XVII. Anuario de Estudios Americanos [en línea]. 2017, vol. 74, n. 2, pp. 461-490. [Consulta: 20-07-2020] Disponible en: $<$ http://estudiosamericanos.revistas.csic.es/index.php/estudiosamericanos/article /view/718/718>.

QUARLERI, Lía. Autonomía y buen gobierno. Conflictos internos de la orden jesuita en la provincia del Paraguay (Córdoba y La Rioja, 1680-1720). Cuadernos de Historia, Serie Ec. y Soc. 2005, n. 5, pp. 153-186.

RAMOS PÉREZ, Demetrio. Historia de la colonización española en América. Madrid: Pegaso, 1947.

RAWLINGS, Helen. Las órdenes religiosas y la crisis en el nombramiento de obispos en Castilla bajo Felipe IV (1621-1665). Manuscrits. Revista d'Història Moderna [en línea]. 2012, n. 30, pp. 125-137. [Consulta: 22-07-2020]. Disponible en $<$ https://revistes.uab.cat/manuscrits/article/view/v30-rawling $>$.

RIVERO RODRÍGUEZ, Manuel. La edad de oro de los virreyes. El virreinato en la Monarquía Hispánica durante los siglos XVI y XVII. Madrid: Ediciones Akal S.A., 2011.

RIVERO RODRÍGUEZ, Manuel. La reconstrucción de la Monarquía Hispánica: la nueva relación con los reinos (1648-1680). Revista Escuela de Historia [en línea]. 2013, vol. 12. [Consulta: 15-07-2019] $<$ http://www.scielo.org.ar/scielo.php?script=sci arttext\&pid=S166990412013000100002>.

ROSANVALLON, Pierre. Por una historia conceptual de lo político. Buenos Aires: Fondo de Cultura Económica, 2003.

SÁNCHEZ-ARCILLA BERNAL, José, LOSA CONTRERAS, Carmen y MORANCHEL POCATERRA, Mariana. Instituciones políticos-administrativas de la América Hispana (1492-1810). Madrid: Universidad Complutense de Madrid, 1999.

SANTOS LEPERA, Lucía y FOLQUER, Cynthia (coords.). Las comunidades religiosas, entre la política y la sociedad. Colección Historias temáticas de Tucumán, siglo XIX y XX. Ediciones Imago Mundi, 2017.

SARTORI MOYANO, Federico Tulio. Al sur de las hogueras. Inquisición y sociedad en Córdoba del Tucumán durante los siglos XVI y XVII. Córdoba: Universidad Nacional de Córdoba, 2020. 
SIERRA, Vicente. Historia de la Argentina, Consolidación de la labor pobladora (1600-1700) Libro Primero: Bajo el reinado de Felipe III. Buenos Aires: Editorial Científica, 1953.

SIRINELLI, Jean-François. El retorno de lo político. Historia Contemporánea. 1993, vol. 25, n. 9.

SKINNER, Quentin. Visions of politics. Vol. I-III. Cambridge: Cambridge University Press, 2002.

STONE, Lawrence. History and the social sciences in the twentieth century. The past and de present Revisited. Boston-Londres-Henley, 1981.

SUÁREZ, Margarita (ed.). Parientes, criados y allegados: los vínculos personales en el mundo virreinal peruano. Lima: PUCP-Instituto Riva-Agüero, 2017.

TANDETER, Enrique (dir.). Nueva Historia Argentina. La sociedad colonial. T. II. Buenos Aires: Sudamericana, 2000, pp. 358-411.

TAU ANZOÁTEGUI, Victor. La Monarquía. Poder central poderes locales. En: Nueva Historia de la Nación Argentina. Segunda parte: La Argentina de los siglos XVII y XVIII. Academia Nacional de la Historia. Buenos Aires: Editorial Planeta, 1999.

TELECHEA IDÍGORAS, José. El obispo ideal según el Concilio de Trento. En: MOZZARELLI, Cesare y ZARDIN, Danilo (ed.). I tempi del Concilio: Religione, cultura e società nell'Europa tridentina. Roma: Bulzoni, 1997, pp. 207-223.

TORRES ARANCIVIA, Eduardo. Corte de virreyes: el entorno del poder en el Perú en el siglo XVII. Lima: Fondo Editorial PUCP, 2006.

TOSCANO, Julián. El Primitivo Obispado del Tucumán y la Iglesia de Salta. T. I. Buenos Aires: Imprenta M. Biedma, 1937.

TRUJILLO, Oscar. Los Gobernadores de Buenos Aires a mediados del siglo XVII: mediación y conflicto en los confines de la Monarquía Hispánica. Historia, historias. 2014, vol. 2, n. 3, pp. 92-108.

TURNER BUSHNELL, Amy y GREENE, Jack. Peripheries, Centers and the Construction of Early Modern American Empires. An Introduction. En: DANIEL, Christine y KENNEDY, Michael (eds.). Negotiated Empires: Centres and Peripheries in the Americas, 1500-1820. Nueva York-Londres, 2002, pp. 1-15.

ZAVALA, Silvio. Las instituciones jurídicas en la conquista de América. Editorial Porrúa, 1971.

ZAVALA, Silvio. Ensayos sobre la colonización española en América. Secretaría de educación pública, 1972. 